Copyright

by

Nathan Francis Swem

2016 
The Dissertation Committee for Nathan Francis Swem certifies that this is the approved version of the following dissertation:

\section{Information in Financial Markets: Who Gets It First?}

Committee:

Sheridan Titman, Supervisor

Aydogan Alti

Michael Clement

Travis Johnson

Clemens Sialm

Laura Starks 


\title{
Information in Financial Markets: Who Gets It First?
}

\author{
by \\ Nathan Francis Swem, B.A., M.S.Fin. \\ DISSERTATION \\ Presented to the Faculty of the Graduate School of \\ The University of Texas at Austin \\ in Partial Fulfillment \\ of the Requirements \\ for the Degree of \\ DOCTOR OF PHILOSOPHY
}

THE UNIVERSITY OF TEXAS AT AUSTIN

May 2016 
I dedicate this work to the memory of my mother Janet Swem. 


\section{Acknowledgments}

I thank my dissertation committee: Sheridan Titman (chair), Aydogan Alti, Michael Clement, Travis Johnson, Clemens Sialm, and Laura Starks for five years of invaluable guidance, support, and insight. I thank Taylor Nadauld for his critical role in inspiring me to pursue a Ph.D degree, and for support along the way. I thank Andres Almazan for accepting me into the Finance Ph.D program, and critical support through the first year as well as guidance since then. I thank the above as well as Jonathan Cohn, Nicholas Crain, Neal Ghosh, Lauren Hodges, Nichole Liu, Zack Liu, Richard Lowery, David Maccarrone, Gonzalo Maturna, Alessio Saretto, Avi Schiff, Ina Taneva, Mitch Towner, Parth Venkat, and Adam Winegar for engaging in countless discussions, attending presentations, and for generous help and support along the way. I thank David Kostin for help with data for this research, and for support and inspiration while at Goldman Sachs. I thank former colleagues at Longbow Capital Partners including Terry Fitzgerald, Stan Furman, Steven Gambuzza, and Steven Strassberg, as well as former colleagues at Goldman Sachs including Jessica Binder, Abby Cohen, Terry Darling, David Chiaro, Brad Handler, and Rob Koyfman for inspiration and support. Finally, I thank my loving family and wonderful group of friends for inspiration, support, and for keeping my spirits up. 


\title{
Information in Financial Markets: Who Gets It First?
}

\author{
Publication No. \\ Nathan Francis Swem, Ph.D. \\ The University of Texas at Austin, 2016
}

Supervisor: Sheridan Titman

I compare the timing of information acquisition among institutional investors and analysts, and I show that hedge fund trades predict the direction of subsequent analyst ratings change reports. I also show individual hedge funds persistently predict the reports of specific analysts. In addition, following analyst reports, hedge funds reverse their prior trades. These patterns suggest hedge funds have greater information acquisition skill relative to analysts, and that hedge funds privately communicate with certain analysts. Finally, I show hedge funds perform best among stocks with high analyst coverage, which suggests that analysts assist hedge funds in exploiting information acquisition advantages. 


\section{Table of Contents}

Acknowledgments $\quad$ v

Abstract vi

List of Tables ix

List of Figures $\quad$ x

Chapter 1. Hedge Funds: An Overview 1

1.1 What Are Hedge Funds? . . . . . . . . . . . . . . . . . 2

1.2 Hedge Fund Performance . . . . . . . . . . . . . . . . . . 5

1.3 How Hedge Fund Trades Affect Markets . . . . . . . . . . . . . 7

1.4 Hedge Fund Activism and Corporate Finance . . . . . . . . . . 8

\section{Chapter 2. Information in Financial Markets:}

Who Gets It First? 14

2.1 Introduction . . . . . . . . . . . . . . . . . . 14

2.2 Data and Variables Construction . . . . . . . . . . . . . . . 21

2.2.1 The Hedge Fund Sample . . . . . . . . . . . . . . . . . 22

2.2.2 The Mutual Fund Sample . . . . . . . . . . . . . . 23

2.2.3 Variables that Summarize Hedge Fund and Mutual Fund

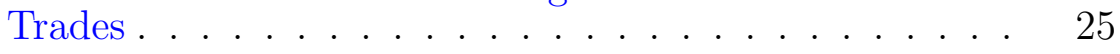

2.2.4 Variables that Summarize the Direction of Analyst Ratings Change Reports . . . . . . . . . . . . 27

2.2.5 Hedge Fund - Analyst Coverage Overlap . . . . . . . . . 29

2.2.6 Tercile Sorting Methodology . . . . . . . . . . . . . 30

2.2.7 Control Variables and Panel Characteristics . . . . . . . 31

2.3 Results . . . . . . . . . . . . . . . . . . 32

2.3.1 Are Hedge Funds or Mutual Funds Early-Informed Relative to Analysts? . . . . . . . . . . . . . . . . 
2.3.2 Hedge Funds Predicting Analysts: Estimating Economic Magnitudes . . . . . . . . . . . . . . . . 34

2.3.3 Hedge Fund and Mutual Fund Responses to Analyst Reports ...................... 37

2.3.4 Hedge Fund Performance and Analyst Coverage . . . . . 40

2.3.5 Analysts "Tipping" Hedge Funds . . . . . . . . . . . . . 43

2.3.6 Which Hedge Funds Best Anticipate Analysts? . . . . . 47

2.3.7 Do Individual Hedge Funds Persistently Predict Individual Analysts?. . . . . . . . . . . . . . . . 50

2.4 Conclusion . . . . . . . . . . . . . . . . . . 53

$\begin{array}{ll}\text { Appendices } & 68\end{array}$

$\begin{array}{lll}\text { Appendix A. Robustness Tests } & 69\end{array}$

A.0.1 Additional Information Proxy Variables for Hedge Funds and Mutual Funds . . . . . . . . . . . . . . 69

A.0.2 Tests Using Additional Information Proxy Variables . . 70

$\begin{array}{ll}\text { Bibliography } & 72\end{array}$

viii 


\section{List of Tables}

1.1 Hedge Fund and Mutual Fund Summary Statistics . .

1.2 Summary of Largest Hedge Funds and Mutual Funds in Each Sample . . . . . . . . . . . . . . . . . .

1 Hedge Fund, Mutual Fund, and Analyst Summary Statistics .................... 56

2 Regressions Variables Summary Statistics . . . . . . . 57

3 Investor Trades Before Analyst Reports . . . . . . . . 58

4 Hedge Fund And Analysts - Count Regressions . . . . 59

5 Hedge Fund and Mutual Fund Trades After Analyst Reports . . . . . . . . . . . . . . . . . . 60

$6 \quad$ Hedge Fund and Mutual Fund Performance by Size . . 61

7 Hedge Fund and Mutual Fund Performance by Analyst Coverage . . . . . . . . . . . . . . . . . . . 62

8 Hedge Fund Trades Before Analyst Reports - Coverage Terciles . . . . . . . . . . . . . . . . . . . . 63

$9 \quad$ Hedge Fund Trades Before Analyst Reports - Months 64

10 Hedge Fund Trades Before Analyst Reports - Earnings Seasons . . . . . . . . . . . . . . . . . . 65

11 Different Hedge Funds and Analyst Reports . . . . . 66

12 Individual Hedge Funds and Individual Analysts . . . . 67

1 Investor Trades and Analyst Reports - Alternative Measures . . . . . . . . . . . . . . . . 71 


\section{List of Figures}

1.1 Number of Unique 13-F filing Institutions . . . . . . . . 10

1.2 Size and Share of 13-F filing Hedge Funds . . . . . . . . 11

2.1 Timing of Analyst Reports . . . . . . . . . . . . . 55 


\section{Chapter 1}

\section{Hedge Funds: An Overview}

Over the past 15 years, in the United States, hedge funds have grown dramatically in number and in size. As a result, hedge funds are an increasingly important force in financial markets.

Specifically, in Table 1.1, I show that the number of hedge funds, in my sample of 13-F filing hedge funds, has increased from around 450 in 2004, to over 800 by the end of $2014 .^{1}$ In addition to growing in number, hedge funds have also grown in assets under management in both absolute terms, and as a share of all 13-F institutional holdings. As I show in Table 1.2, as of yearend 2014, hedge funds that file 13-Fs with the United States Securities and Exchange Commission (SEC) hold more than $\$ 1.2$ trillion worth of equities long positions, which represents more than $8 \%$ of all equities positions held by 13-F filing institutions. ${ }^{2}$

\footnotetext{
${ }^{1}$ The hedge funds represent only those funds large enough to require filings with the SEC. The SEC requires institutional investment managers with more than $\$ 100$ million in exchange-traded or NASDAQ-quoted equity securities to file $13-\mathrm{F}$ reports within 45 days of the end of each calendar quarter for all equity positions greater than 10,000 shares or $\$ 200,000$ in market value.

${ }^{2} \mathrm{My}$ process for identifying hedge funds in the Thomson Reuters data is consistent with Brunnermeier and Nagel (2004), Griffin and Xu (2009), Ben-David, Franzoni, and Moussawi (2012), and Agarwal, Fos, and Jiang (2013) which use various methods to identify hedge funds, and then query the Thomson Reuters $13-\mathrm{F}$ data to assemble hedge fund holdings.
} 
In this section I describe exactly what a hedge fund is, how hedge

funds are regulated, and how these regulations make hedge funds a unique and important force in financial markets. I also survey the academic literature relating to hedge fund manager skill, how hedge funds impact financial markets through their trades, and how hedge funds impact decisions of corporate management teams through activism.

\subsection{What Are Hedge Funds?}

Hedge funds are investment firms that manage capital for a fee. Hedge funds are generally organized as partnerships or limited liability companies, and employ a team of professional managers to implement the fund's investment strategies. Critically, hedge funds can only accept capital from a limited number of accredited investors - which are generally very high-net-worth individuals and institutions such as pension funds and endowment funds. Due to these restrictions on the type and number of investors, regulatory agencies in the United States (such as the SEC) treat hedge funds differently than other institutional asset management companies that manage capital on behalf of individuals such as mutual funds. These differences in regulations result in hedge funds facing different incentives and having fewer constraints, which I describe below.

Another important difference between hedge funds and other institutional investment companies, such as mutual funds, relates to the regulation of incentive based compensation. As outlined in Starks (1987), Ackermann, 
McEnally, and Ravenscraft (1999), and Stulz (2007), SEC regulations require that performance-based mutual fund management company fee compensation mechanisms be symmetric. Therefore, performance based compensation mechanisms that reward the management companies for positive investment performance must also equally detract from compensation for poor (or negative) investment performance relative to a benchmark. ${ }^{3}$ Hedge funds are not regulated in this way, which allows hedge funds to employ asymmetric performance based compensation mechanisms. ${ }^{4}$ For this reason, hedge funds generally charge an annual management fee as a percentage of assets under management, plus an annual performance fee in the form of a percentage of any investment profits.

Another significant difference between hedge funds and mutual funds relates to investor redemptions liquidity. Investors can liquidate investments in most mutual funds on a daily basis, as required by securities laws. In contrast, investors liquidating investments in hedge funds face a more involved process, as most hedge funds negotiate lock-up periods (also called gates) that limit redemptions to quarterly or annual frequency. These investment liquidations mechanisms for hedge funds are designed to protect hedge funds from fire sale liquidation pressures resulting from redemptions, as shown in Coval and

\footnotetext{
${ }^{3}$ Managers of mutual funds can be paid asymmetrically by the mutual fund management company.

${ }^{4}$ For example, most hedge funds charge an annual management fee of 1-2\% of assets under management, which is similar in structure to mutual funds. However, in addition, most hedge funds change an annual performance fee of $20 \%$ of profits generated by the fund's investment strategy. While these percentages vary for different hedge funds, generally hedge funds do not return a "negative" performance fee for losses, which implies the performance compensation mechanism is asymmetric.
} 
Stafford (2007).

The final major distinction between hedge funds and mutual funds that I discuss in this article relates to the regulation of information disclosures. Unlike mutual funds, hedge funds are not required to publicly disclose their size, investment performance, or fees. The only notable public disclosures the SEC requires for hedge funds are the long positions in equities securities reported quarterly on form $13-\mathrm{Fm}$ provided the fund holds more than $\$ 100$ million in AUM. The SEC does not require that institutional investors disclose short positions, which comprise a significant aspect of most hedge fund investment strategies, as discussed below. Therefore, form 13-F's are a less comprehensive disclosure for hedge fund portfolios than for other institutional investors that do not employ short-selling, such as most pension funds and most mutual funds.

As a result of the regulations outlined above, hedge fund managers generally have more direct performance incentives and more flexibility in implementing investment strategies relative to mutual funds. I show summary statistics for my sample of hedge funds and mutual funds in Table 1.1. Hedge funds are generally smaller, and manage more highly concentrated portfolios than the average mutual fund. In addition, hedge fund strategies involve higher turnover on average relative to strategies run by mutual funds. Finally, the hedge funds in my sample tend to hold portfolios that are more highly concentrated within-industry than my sample of mutual funds. ${ }^{5}$ I show the details of

\footnotetext{
${ }^{5}$ I identify actively managed mutual funds from the over 35,000 individual mutual funds
} 
the largest hedge funds and mutual fund 13-F filers in Table 1.2. The largest hedge funds are much smaller than the largest mutual funds, but the largest hedge funds generally have far higher turnover than the largest mutual funds.

\subsection{Hedge Fund Performance}

Hedge funds generally use leverage, which allows for shorting and the use of derivatives. By contrast, according to Almazan et al. (2004), more than $60 \%$ of mutual funds voluntarily constrain themselves by not allowing shortselling. Taken together with the regulatory differences outlined above, hedge funds generally have more flexibility and face fewer constraints in employing investment strategies relative to mutual funds. However, because hedge funds are not required to disclose portfolio returns, empirically evaluating hedge fund performance presents significant challenges for researchers seeking to examine how effectively hedge funds exploit their apparent advantages relative to mutual funds.

Nevertheless, several databases exist for hedge fund performance due to voluntary disclosure. While these data are generally voluntary and not comprehensive, as discussed in detail in Kosowski, Naik, and Teo (2007), both that paper and Ibbotson and Chen (2005) find evidence from hedge fund per-

in the Thompson Reuters S12 holdings data from 2004-2014. I filter mutual funds following Kacperczyk, Sialm, and Zheng (2008). Then, I exclude all Vanguard index funds, iShares index funds, Proshares index funds, Rydex index funds, SPDR index funds, and all other funds that contain words such as index, inde, ex, as well as numbers 1000, 2000, 3000, 500, 400, and 600 in their name. I also exclude the Nasdaq QQQ index fund. 
formance databases that hedge funds generate positive risk-adjusted returns.

In addition, Griffin and Xu (2009) employs a different approach to examining hedge fund performance: aggregating returns from the hedge fund positions in quarterly 13-F filings. When portfolio performance is calculated in this way, Griffin and Xu (2009) shows that hedge funds outperform mutual funds by roughly 2 percentage points per year, which is similar to my own findings discussed in the next chapter.

It is possible that hedge funds derive investment performance from short-selling activities, which cannot be examined using hedge fund 13-F filings. Many papers examining short interest data, such as Senchack and Starks (1993) and Christophe, Ferri, and Angel (2004), suggest that increases in short interest, at the stock level, precede negative stock returns and negative earnings announcements. These findings suggest that short sellers have some degree of investment skill. Hedge funds regularly employ short selling strategies, although the lack of disclosures make these activities all but impossible to evaluate in a comprehensive manner.

Finally, intra-quarter trading by hedge funds may provide additional investment outperformance, especially considering hedge funds generally employ higher-turnover strategies than mutual funds as shown in 1.1. However, lack of performance disclosures for hedge funds, as discussed above, makes it impossible to perform a comprehensive analysis of such unobserved trading actions for hedge funds, such as Kacperczyk, Sialm, and Zheng (2008) shows for mutual funds. 


\subsection{How Hedge Fund Trades Affect Markets}

The manner in which hedge fund trading activity affects markets is a somewhat controversial topic in academic literature. While French (2008) documents the rise of institutions in markets, Stein (2009) points out the rise of particularly sophisticated institutions, such as hedge funds, might have implications for market efficiency. Specifically, sophisticated investors that employ trading strategies not anchored to fundamental value might drive prices away from fundamental value. In support of the theory that sophisticated investors, such as hedge funds, can drive prices away from fundamental value Brunnermeier and Nagel (2004) find that hedge funds exerted a destabilizing force in the late 1990's technology bubble.

In contrast, several other papers, including my own research, show that hedge funds play a significant role in acquiring fundamental information and incorporating this information into securities prices. Specifically, several recent papers show that hedge funds aggressively employ novel information acquisition methods, including: Solomon and Soltes (2013) which examines private meetings with company management teams, Jeng (2013) which examines "expert networks," and Gargano, Rossi, and Wermers (2014), which shows that hedge funds frequently file Freedom of Information Act (FOIA) requests with federal government agencies to acquire non-public information relating to portfolio companies such as the results of ongoing government mandated drug trials and other important regulatory approvals or restrictions.

In addition to the information acquisition practices outlined above, 
Agarwal et al. (2013) shows hedge funds are most aggressive in lobbying the SEC to hide the portfolio positions of small, low analyst coverage stocks from 13-F filings. These findings suggest hedge funds believe publishing their positions will allow investors to infer fundamental information about stocks. In support of this notion Verbeek and Wang (2013) finds evidence of hedge fund "copycat" investors who glean information from hedge fund 13-F filings.

Finally, Ljungqvist and Qian (2014) examines a sample of hedge funds that publish reports containing fundamental information about portfolio positions, in a similar manner to sell-side analysts. By publishing reports about stocks, these hedge funds seek to proactively incorporate fundamental information in stock prices more quickly, and side-step limits to arbitrage such as short-sale constraints. This practice is consistent with anecdotal evidence of information disclosures by large hedge fund managers about portfolio positions in public forums, such as the annual Ira Sohn Conference. ${ }^{6}$

\subsection{Hedge Fund Activism and Corporate Finance}

Hedge funds play an increasingly significant role in corporate governance and capital structure as a result of investor activism. Activist campaigns led by hedge funds have become increasingly frequent over the past several years, as innovations in corporate takeover defense mechanisms, such

\footnotetext{
${ }^{6}$ Notable examples include David Einhorn of Greenlight Capital discussing The St. Joe Company (JOE) in 2010, and William Ackman of Pershing Square Capital discussing Herbalife (HLF) in 2012.
} 
as poison pills and staggered boards, have rendered hostile takeover strategies increasingly ineffective. However, activism allows a minority shareholder to solicit votes from other shareholders to affect change at a target firm, such as a payout increase, without a change in control.

Hedge funds are particularly well suited for executing effective activist campaigns. As outlined in Brav et al. (2008), hedge funds face fewer conflicts of interest than other activists including pension funds, which may have closer relationships with potential target firms. In addition, the regulations for hedge funds outlined above generally allow hedge funds greater flexibility in portfolio concentration and position duration. These characteristics make hedge funds especially effective activists.

In addition, Brav, Jiang, and Kim (2009) show that activist hedge funds tend to result in durable improvements in target firm performance. Specifically, target firms tend to have higher payouts, higher leverage, higher returns of capital, and are more likely to engage in spin-offs and mergers than comparable peer firms. Target firm stock returns also exceed those of comparable firms. These effects suggest activist hedge funds not only choose targets effectively, but also affect the management of the target firms in a way that improves fundamentals.

Finally, Clifford (2008) shows that hedge funds generate higher returns from activist positions relative to passive positions. This suggests that not only are hedge fund activists important in affecting target firms, but also activism is an important aspect of hedge fund performance. 


\section{Figure 1.1: Number of Unique 13-F filing Institutions}

This figure shows the number of unique 13-F filing institutions in the Thomson Reuters 13-F holdings data. The institutions have been grouped according to whether the institutions is a hedge fund or not a hedge fund. The data include quarters from 2004-2014.

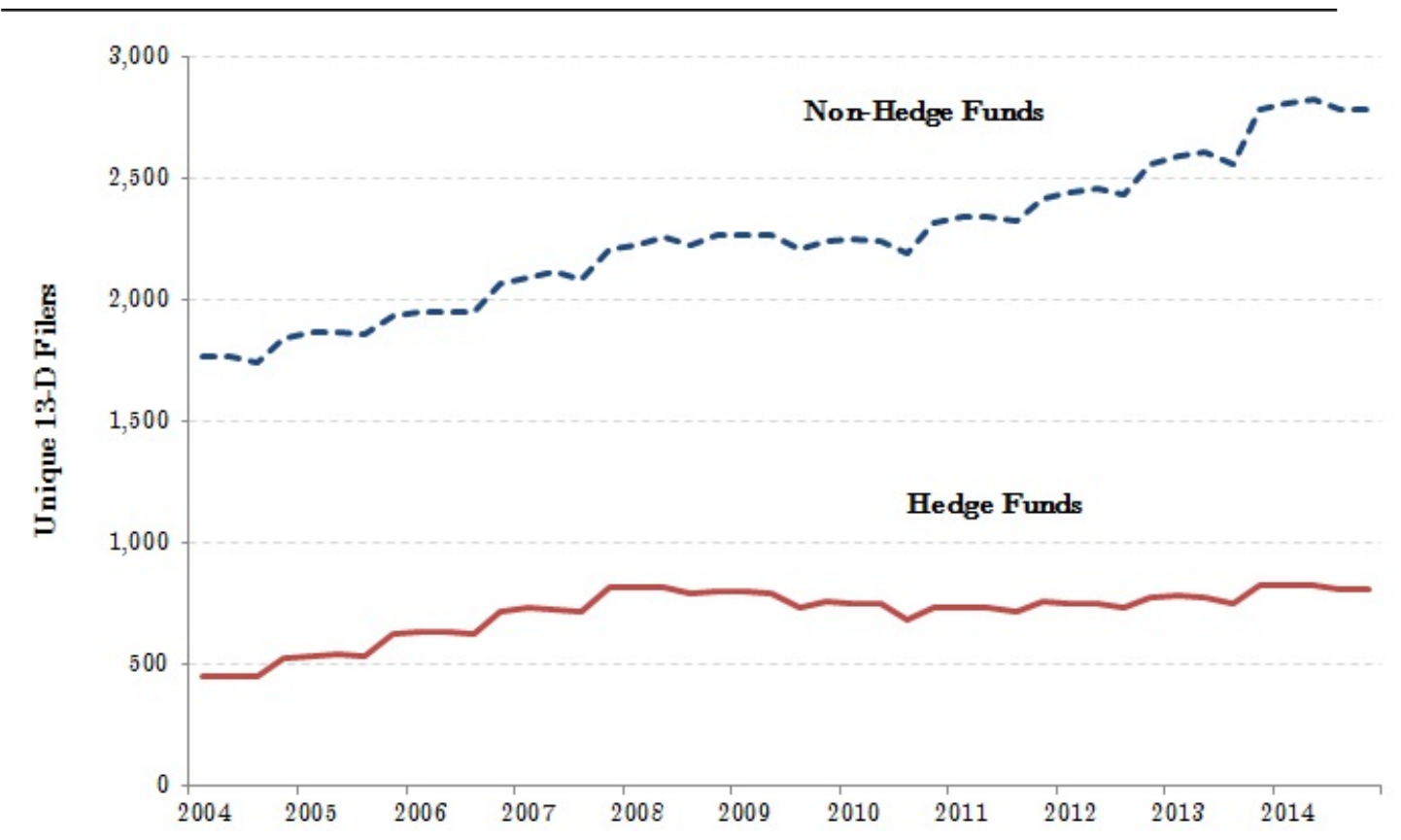




\section{Figure 1.2: Size and Share of 13-F filing Hedge Funds}

This figure shows the aggregate value of equities long positions unique 13-F filing institutions in the Thomson Reuters 13-F holdings data, and the share of equities long positions held by hedge funds as a share of all positions in the 13-F holdings data. The data include quarters from 2004-2014.

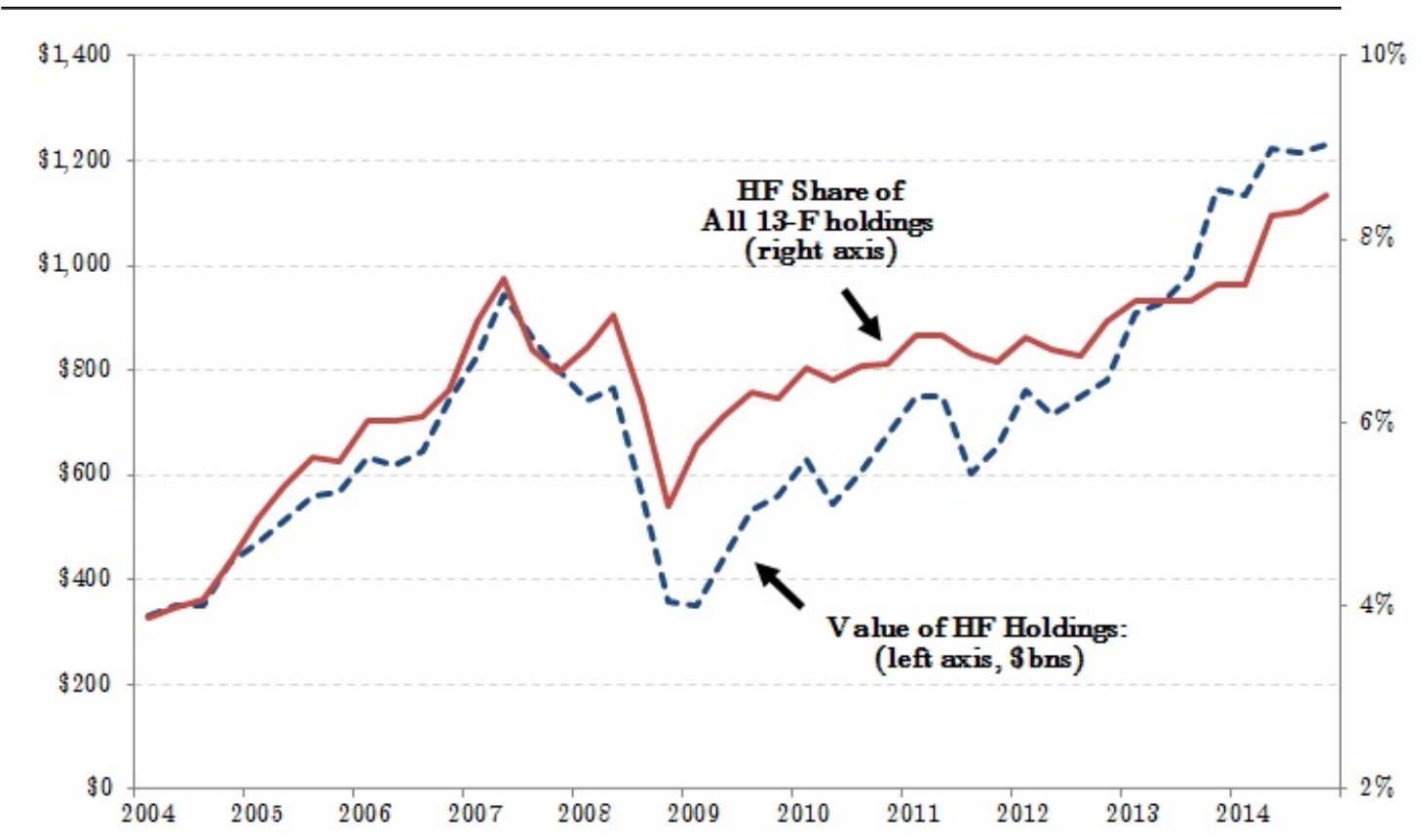




\section{Table 1.1: Hedge Fund and Mutual Fund Summary Statistics}

This table presents summary statistics for my sample of hedge funds and mutual funds. I describe the selection of the hedge fund and mutual fund samples in Sections 2.2.1 and 2.2.2. The summary statistics presented below for portfolio size (in $\$$ millions), number of positions, turnover, and industry concentration (based on the ICI measure defined in Kacperczyk, Sialm, and Zheng (2005)) reflect averages for each fund over the time-series of the sample. The data are quarterly from 2004-2014.

\begin{tabular}{llllllc}
\hline \hline & Mean & Median & Std Dev & Min & Max & $\mathrm{n}$ \\
\hline Hedge Funds & & & & & & \\
Portfolio Size & $\$ 666$ & $\$ 209$ & $\$ 1,653$ & $\$ 0.1$ & $\$ 27,593$ & 1,436 \\
Number of Pos & 82 & 33 & 183 & 1 & 2,420 & 1,436 \\
Turnover & $25 \%$ & $24 \%$ & $15 \%$ & $0 \%$ & $89 \%$ & 1,436 \\
Ind Concentration & 0.20 & 0.13 & 0.19 & 0.00 & 1.14 & 1,436 \\
& & & & & & \\
Mutual Funds & & & & & & \\
Portfolio Size & $\$ 1,168$ & $\$ 234$ & $\$ 4,025$ & $\$ 0.01$ & $\$ 90,769$ & 2,053 \\
Number of Pos & 101 & 65 & 154 & 1 & 2,578 & 2,053 \\
Turnover & $13 \%$ & $12 \%$ & $7 \%$ & $0 \%$ & $48 \%$ & 2,053 \\
Ind Concentration & 0.12 & 0.05 & 0.20 & 0.00 & 1.10 & 2,053 \\
\hline \hline
\end{tabular}




\section{Table 1.2: Summary of Largest Hedge Funds and Mutual Funds in Each Sample}

This table presents the names of the 30 largest hedge funds and mutual funds in my respective samples as ranked by the quarterly average value of equity holdings according to the 13-F holdings data. Size is the total value (in billions) of all equity holdings each quarter, averaged over the quarters from 2004-2014 during which each fund was in the sample. Turn is the average quarterly portfolio turnover of the fund. Number of positions (\#Pos) is the average number of holdings each quarter. The manner in which the sample of hedge funds and mutual funds are identified and assembled is outlined the Data section. Some hedge fund and mutual fund names were abbreviated, and designations such as Inc., LLC, LC, etc. have been removed.

\begin{tabular}{|c|c|c|c|c|c|c|c|}
\hline \multicolumn{4}{|l|}{ Hedge Funds } & \multicolumn{4}{|l|}{ Mutual Funds } \\
\hline Name & Size & Turn & \#Pos & Name & Size & Turn & \#Pos \\
\hline Renaissance Technologies & 30 & 0.35 & 2,568 & Growth Fd of America & 101 & 0.07 & 221 \\
\hline D. E. Shaw \& Co. & 29 & 0.20 & 1,907 & Washington Mutual Invest & 61 & 0.05 & 123 \\
\hline Citadel Investment Group & 21 & 0.36 & 2,221 & Fidelity ContraFd & 61 & 0.12 & 327 \\
\hline Adage Capital Mgmt & 20 & 0.18 & 604 & Investment Company of Am & 53 & 0.05 & 132 \\
\hline AQR Capital Mgmt & 12 & 0.18 & 1,586 & Dodge \& Cox Stock Fd & 44 & 0.04 & 78 \\
\hline Millennium Mgmt & 12 & 0.37 & 2,407 & Fundamental Investors & 33 & 0.07 & 151 \\
\hline Paulson \& Co. & 11 & 0.23 & 52 & Fidelity Growth Company & 33 & 0.10 & 280 \\
\hline Acadian Asset Mgmt & 11 & 0.26 & 685 & Income $\mathrm{Fd}$ of America & 32 & 0.07 & 103 \\
\hline Lone Pine Capital & 11 & 0.24 & 43 & Vanguard Wellington Fd & 31 & 0.06 & 95 \\
\hline S.A.C. Capital Advisors & 10 & 0.44 & 1,370 & Fidelity Magellan Fd & 31 & 0.13 & 197 \\
\hline Two Sigma Investments & 9 & 0.48 & 1,687 & American Balanced Fd & 31 & 0.06 & 99 \\
\hline Icahn \& Company & 9 & 0.03 & 12 & Vanguard Primecap Fd & 28 & 0.02 & 117 \\
\hline ESL Investments & 9 & 0.01 & 7 & Davis New York Venture & 26 & 0.05 & 61 \\
\hline Maverick Capita & 9 & 0.32 & 71 & Capital Income Builder & 23 & 0.05 & 85 \\
\hline Viking Global Investors & 8 & 0.37 & 62 & Fidelity Low Priced Stock & 22 & 0.06 & 417 \\
\hline HAP Trading & 7 & 0.02 & 1,483 & T Rowe Price Growth Stock & 21 & 0.09 & 97 \\
\hline Highfields Capital Mgmt & 7 & 0.17 & 72 & T Rowe Price Equity Inco & 20 & 0.04 & 115 \\
\hline Glenview Capital Mgmt & 7 & 0.21 & 57 & AMCAP Investment Port & 19 & 0.06 & 131 \\
\hline Gateway Invt Advisers & 7 & 0.03 & 596 & Franklin Income Fd-US & 18 & 0.06 & 55 \\
\hline Orbis Investment Mgmt & 7 & 0.14 & 38 & Fidelity Equity Income & 17 & 0.08 & 184 \\
\hline Highbridge Capital Mgmt & 7 & 0.39 & 998 & Vanguard Health Care Fd & 17 & 0.03 & 61 \\
\hline Och-Ziff Capital Mgmt Grp & 6 & 0.34 & 194 & Fidelity Blue Chip Growth & 16 & 0.16 & 198 \\
\hline Kayne Anderson Cap & 6 & 0.07 & 125 & American Mutual Fd & 16 & 0.05 & 127 \\
\hline Gilder Gagnon Howe \& Co. & 6 & 0.14 & 236 & T Rowe Price Mid Capital & 15 & 0.08 & 137 \\
\hline Marathon Asset Mgmt & 5 & 0.06 & 81 & Vanguard Windsor Fd & 15 & 0.11 & 135 \\
\hline Longview Ptnr & 5 & 0.07 & 18 & Fidelity Growth \& Income & 14 & 0.14 & 146 \\
\hline Pershing Square Cap Mgmt & 5 & 0.12 & 7 & Columbia Acorn Fd & 14 & 0.06 & 298 \\
\hline UBS O'Connor & 5 & 0.35 & 678 & Riversource New Dimension & 14 & 0.10 & 98 \\
\hline Guggenheim Capital & 5 & 0.15 & 741 & Fidelity Puritan Fd & 13 & 0.15 & 216 \\
\hline Caxton Associates & 5 & 0.37 & 836 & Eaton Vance Tax Managed & 13 & 0.02 & 413 \\
\hline Atticus Capital & 5 & 0.23 & 80 & MFS Value Fd & 13 & 0.06 & 83 \\
\hline Pointstate Capital & 5 & 0.38 & 110 & Lord Abbett Affiliated & 12 & 0.12 & 105 \\
\hline WG Trading Co. & 5 & 0.00 & 487 & T Rowe Price Blue Chip & 12 & 0.09 & 127 \\
\hline Valueact Capital Mgmt & 5 & 0.09 & 15 & Fidelity Balanced Fd & 12 & 0.16 & 350 \\
\hline
\end{tabular}




\section{Chapter 2}

\section{Information in Financial Markets: Who Gets It First?}

\section{$2.1 \quad$ Introduction}

Institutional investment firms and analysts at brokerage firms play prominent roles in incorporating information into stock prices. Investors incorporate their information through trades, and analysts incorporate their information by disseminating research reports. While the publicly available information generated by analysts has been extensively studied, information generated privately by the research staff employed by investment firms is harder to examine and less well understood. In addition, the manner in which investors and analysts interact with one another as they gather information, and the degree to which these interactions affect markets, is also not well understood.

In this paper, I examine the activities of hedge funds, mutual funds, and analysts to determine who tends to acquire information first. Specifically, I examine the aggregated trades of hedge funds and mutual funds before and after analyst upgrade and downgrade reports, and I show that hedge fund trades tend to anticipate analyst reports, while mutual fund trades do not. I also find that the trades of individual hedge funds persistently predict the 
reports of specific analysts, which suggests evidence of private information communications between hedge funds and analysts. I also show that hedge funds reverse trades shortly after analysts publish their reports, while mutual funds follow the analysts. Finally, I show that hedge funds outperform mutual funds most strongly among large stocks with high analyst coverage. These results suggests that analysts assist early-informed hedge funds in exploiting their information acquisition skill.

I aggregate the number of hedge funds and mutual funds that buy and sell each stock each quarter using 13-F filings, and show a statistically and economically significant positive relation between the number of hedge funds buying a stock in one quarter and the direction of analyst upgrade and downgrade reports published in the following quarter. My results indicate that a one standard deviation increase in hedge fund buying increases the odds of an analyst upgrade in the following quarter by 3-4 percentage points, and decreases the odds of a subsequent analyst downgrade by 1 percentage point. Similarly, a one standard deviation increase in hedge fund selling increases the odds of a subsequent analyst downgrade by 3 percentage points, and decreases the odds of subsequent upgrade reports by 1 percentage point. In contrast, the net direction of mutual fund buying and selling has no statistical relation with subsequent analyst upgrade and downgrade reports.

I also find that hedge funds and mutual funds respond very differently to analyst information, which further illustrates significant differences between hedge funds, mutual funds, and analysts with respect to information acqui- 
sition. Abnormal $[-1,+1]$ returns average $3.6 \%$ on the announcement of the analyst upgrade reports in my sample, suggesting that analyst reports contain economically significant new information. Following analyst upgrade reports, I find that mutual funds tend to buy. ${ }^{1}$ However, in contrast to mutual funds, I find that hedge funds tend to sell after analyst upgrade reports. I find a similar pattern for analyst downgrade reports. Specifically, stock prices fall an average of $3.7 \%$ in reaction to downgrades, followed by a pattern in which mutual funds sell while hedge funds buy. ${ }^{2}$

The above trading patterns, for both hedge funds and mutual funds, are consistent with theoretical models of investor information and trading. Specifically, my results suggest that hedge funds anticipate analyst upgrade and downgrade reports. They then reverse trades, presumably to take profits, after market prices adjust to the information contained in the analyst reports. These patterns are consistent with the profit-taking trades of early-informed investors in Hirshleifer, Subrahmanyam, and Titman (1994), (hereafter HST).

As additional support of HST, I show that hedge funds outperform mutual funds most strongly among large stocks and, holding size constant, among stocks with high analyst coverage. This pattern is consistent with the

\footnotetext{
${ }^{1}$ My finding that mutual funds follow analysts supports supports prior literature including Kacperczyk and Seru (2007), Busse, Green, and Jegadeesh (2012), and Brown, Wei, and Wermers (2013).

${ }^{2}$ I find that the information contained in analyst upgrade and downgrade reports predict mutual fund trades that occur up to one quarter after the reports are published. This pattern is consistent with the "sidelined" investors modeled in Cao, Coval, and Hirshleifer (2002), who react differently to commonly observed signals such as sudden stock price movements or analyst reports.
} 
early-informed investors in HST, which ex-ante prefer to investigate stocks in which a greater number of later-informed investors will provide liquidity and enable the early-informed investors to eventually unwind trades. In contrast, I find that mutual funds perform most strongly when trading smaller stocks with low analyst coverage, where opportunities for investors to profit from information are most prevalent, as shown in Hong, Lim, and Stein (2000). ${ }^{3}$

My research is closely related to a number of papers that examine how investors, especially hedge funds, become informed. One hypothesis, tested in prior literature, is that certain investors, including hedge funds, become early-informed because analysts privately communicate information to hedge funds before distributing research reports to other investors, in the spirit of the analyst "tipping" examined in Irvine, Lipson, and Puckett (2007). In subsequent papers, both Klein, Saunders, and Wong (2014) and Kadan, Michaely, and Moulton (2014) show that "tipped" investor trades occur within a 1-5 day window immediately before analyst reports are published. This brief window suggests that, in my setting, the trades of "tipped" hedge funds in one quarter should strongly predict the direction of analyst upgrade and downgrade reports published at the very beginning of the following quarter. However, these trades should not predict analyst reports published later into the following quarter.

By exploiting variation in the within-quarter timing of analyst upgrade

\footnotetext{
${ }^{3}$ My results for mutual funds might also explain their preference for smaller and less well-known stocks, or "greener pastures," as shown in Bennett, Sias, and Starks (2003).
} 
and downgrade reports, I test the extent to which analyst "tipping" explains my results. My tests show that hedge fund trades in one quarter predict the direction of analyst reports made in each of the first, second, and third months of the following quarter. These results suggest that analyst tipping cannot entirely explain the degree to which hedge fund trades in one quarter predict the direction of analyst ratings change reports published in the following quarter. These results also rule out the possibility that my results could be explained solely by analysts gleaning information from subsequent hedge fund 13-F filings published mid-way through the following quarter, akin to the "copycat" investors examined in Verbeek and Wang (2013).

I perform additional tests to investigate additional explanations for how hedge funds become early-informed relative to analysts and mutual funds. One explanation is that hedge funds tend to independently acquire similar information as analysts, but they find the information more quickly as a result of superior effort, skill, or technology. Regulations allow for unique links between hedge fund manager compensation and investment performance, which may provide stronger incentives for hedge fund managers to exert effort and/or bear the costs in time and money associated with information generation. ${ }^{4}$ In addition, several recent papers examine novel information acquisition methods ag-

\footnotetext{
${ }^{4}$ Both Ackermann, McEnally, and Ravenscraft (1999) and Stulz (2007) examine the regulatory differences between hedge funds and mutual funds, which contribute to hedge fund compensation being more explicitly linked to fund performance. Groysberg, Healy, and Maber (2011) show that the drivers of analyst compensation are myriad and include measures of stock picking ability, coverage size, recognition in "All-Star" surveys, and investment banking activity among covered companies.
} 
gressively used by hedge funds, including: Solomon and Soltes (2013) which examines private meetings with company management teams, Jeng (2013) which examines "expert networks," and Gargano, Rossi, and Wermers (2014), which shows that hedge funds frequently file Freedom of Information Act (FOIA) requests with federal government agencies.

Finally, I propose the hypothesis that hedge funds establish positions and then privately communicate their information to analysts in the hope that these analysts will publish the hedge fund's information in subsequent reports. By strategically disclosing information to analysts, hedge funds proactively accelerate the incorporation of their information into stock prices. Information disclosures by large hedge fund managers about portfolio positions in public forums, such as the annual Ira Sohn Conference, provide anecdotal support for my hypothesis. ${ }^{5}$ In addition, Ljungqvist and Qian (2014) examines hedge funds that publish reports about portfolio positions, in a similar manner to analysts in order to side step limits to arbitrage. Private communications to analysts provide a disclosure mechanism for hedge funds that prefer to avoid the attention or scrutiny associated with public disclosures.

Empirically identifying unobserved communications with my quarterly trading data poses significant challenges. However, I perform several tests which suggest evidence of private communications of information from hedge

\footnotetext{
${ }^{5}$ Notable examples include David Einhorn of Greenlight Capital discussing The St. Joe Company (JOE) in 2010, and William Ackman of Pershing Square Capital discussing Herbalife (HLF) in 2012.
} 
funds to analysts. Specifically, I find hedge fund trades most strongly predict subsequent analysts reports high analyst coverage stocks (adjusting for size). ${ }^{6}$ In addition, I find that subsequent analyst reports are most strongly predicted by the trades of hedge funds that pay high brokerage fees (i.e. large and high turnover hedge funds), which are most likely to have access to analysts. In addition, I find that subsequent analyst reports are most strongly predicted by the trades of those hedge funds with high industry specialization and high portfolio overlap with covering analysts, which are the hedge funds most likely to have high-quality company-specific information.

I also dis-aggregate the hedge fund holdings and analyst data in order to examine persistence in the extent to which trades of specific hedge funds predict the reports of specific analysts. I divide the sample period in half, and find that an individual hedge fund is $20-30 \%$ more likely to predict a specific analyst in the second half of the sample if the hedge fund predicted the same analyst in the first half. I interpret this persistence as evidence of durable relationships between individual hedge fund managers and individual analysts. These relationships appear to be an economically significant contributing factor for the degree to which hedge fund trades predict analyst information.

My findings support previous literature examining hedge fund and mu-

\footnotetext{
${ }^{6}$ This finding complements Agarwal et al. (2013) which shows hedge funds lobby the SEC to hide the portfolio positions of small, low analyst coverage stocks from 13-F filings in order to mitigate trading costs while initiating portfolio positions. My results suggest that hedge funds proactively disclose information to analysts to accelerate the timing of exiting positions.
} 
tual fund investment performance. Specifically, my results suggest hedge funds tend to acquire information first, which provides a mechanism by which hedge funds generate positive risk adjusted returns, as shown in Ibbotson and Chen (2005) and Kosowski, Naik, and Teo (2007). My results also suggest mutual funds acquire information after hedge funds and analysts, which helps explain prior empirical literature on mutual fund performance including Carhart (1997), Wermers (2000), and Fama and French (2010), which show that mutual fund performance generally falls short of market indexes. In addition, my results support Griffin and $\mathrm{Xu}$ (2009) who use holdings data and show that hedge funds slightly outperform mutual funds.

Finally, my results add to a large empirical literature that examines investor information and investment processes by inferring trades from holdings disclosures, beginning with Grinblatt and Titman (1989). An extensive literature subsequently examines quarterly holdings data to evaluate the performance and investment process of mutual funds and hedge funds, including Daniel et al. (1997), Kacperczyk, Sialm, and Zheng (2008), and Cremers and Petajisto (2009), for mutual funds, and Brunnermeier and Nagel (2004) and Ben-David, Franzoni, and Moussawi (2012) for hedge funds.

\subsection{Data and Variables Construction}

In this section I outline how I assemble over 1,400 unique hedge funds and over 2,000 unique actively managed mutual funds. I also outline my construction of variables summarizing the net direction of hedge fund and mutual 
fund trades in each stock. Finally, I describe my variables characterizing the net direction of buy/sell/hold upgrade and downgrade reports published by the analysts that cover each stock, as well as several other variables.

\subsubsection{The Hedge Fund Sample}

I begin with the sample of over 2,500 hedge fund names listed in the FactSet LionShares holdings data from 2004-2014, as these data identify which 13-F filers are hedge funds. ${ }^{7}$ I check company websites (where available) to ensure that each hedge fund is a "pure play" hedge fund and to remove diversified asset management companies that sponsor mutual funds, and to remove broker-dealers. I then manually cross-check the hedge fund names from FactSet LionShares against the 14,000 unique investment company names in the Thomson Reuters 13-F holdings database from 2004-2014. ${ }^{8}$ The result is a sample of over 1,400 unique hedge funds. The summary statistics for these funds are shown in Table 1.

My process for identifying hedge funds is consistent with Brunnermeier and Nagel (2004), Griffin and Xu (2009), Ben-David, Franzoni, and Moussawi (2012), and Agarwal, Fos, and Jiang (2013) which use various methods to identify hedge funds, and then query the Thomson Reuters 13-F data to

\footnotetext{
${ }^{7}$ Database documents indicate Factset Lionshares classifies institutional style based on: "internal research and other public documents."

${ }^{8}$ The SEC requires institutional investment managers with more than $\$ 100$ million in exchange-traded or NASDAQ-quoted equity securities to file 13-F reports within 45 days of the end of each calendar quarter for all equity positions greater than 10,000 shares or $\$ 200,000$ in market value.
} 
assemble hedge fund holdings. I believe my sample of hedge funds, sourced from FactSet, is at least as comprehensive those used in previous literature related to hedge fund holdings data. I use holdings data from Thomson Reuters because, as discussed in Ben-David, Franzoni, and Moussawi (2012), Thomson Reuters (and subsumed companies such as CDA/Spectrum) has the most comprehensive 13-F holdings data.

My sample of 1,400 hedge funds includes over 6 million unique positions for the quarters from 2004-2014. My sample includes many hundreds of nowdefunct hedge funds and should not be affected by survivorship bias. For any given quarter, the holdings data contain between 600-800 unique hedge funds. The number of active hedge funds grows by more than $25 \%$ over the 44-quarter time series from 2004-2014, and the average and aggregate holdings

grow as well. I apply nominal cleaning measures to adjust the time series of the holdings data for stock splits. I use the holdings data to approximate individual hedge fund and mutual fund quarterly portfolio performance in a manner that is consistent with Kacperczyk, Sialm, and Zheng (2008). I list the names of the largest hedge funds in Table 1.2 of the Appendix, and I present summary statistics for hedge funds in Table 1.

\subsubsection{The Mutual Fund Sample}

I assemble a comprehensive sample of actively managed mutual funds to compare with the above sample of hedge funds. Since 2004, when I begin my sample, the SEC has required that individual mutual funds file quarterly 
holdings disclosures on forms N-30D, N-Q, and N-CSR (instead of its previous policy of requiring bi-annual filings). While mutual fund management companies (e.g. Fidelity Management and Research), file aggregated holdings on form 13-F, the SEC also requires holdings disclosures for individual mutual funds (e.g. Fidelity Contrafund, Fidelity Magellan, Fidelity Blue Chip Growth, etc).

I identify actively managed mutual funds from the over 35,000 individual mutual funds in the Thompson Reuters S12 holdings data from 20042014. I follow Kacperczyk, Sialm, and Zheng (2008) and exclude all funds with "Investment Objective Codes" that correspond to international funds and fixed-income funds, as well as those funds that are unknown or unclassified. Applying these filters results in a sample of fewer than 3,000 unique mutual funds, that appear comparable in number, size, and turnover to those used in Kacperczyk, Sialm, and Zheng (2008). Then, in order to exclude mutual funds likely to employ index strategies I exclude all Vanguard index funds, iShares index funds, Proshares index funds, Rydex index funds, SPDR index funds, and all other funds that contain words such as index, inde, ex, as well as numbers 1000, 2000, 3000, 500, 400, and 600 in their name. I also exclude the Nasdaq QQQ index fund. Applying these mutual fund name filters results in a sample of over 2,000 unique actively managed mutual funds from 20042014. I list the names of largest mutual funds in my sample in Table 1.2 of the Appendix, and I present summary statistics for mutual funds in Table 1. 


\subsubsection{Variables that Summarize Hedge Fund and Mutual Fund Trades}

I use the individual holdings filings to construct variables to proxy for information arrival among my samples of hedge funds and mutual funds for each stock $i$ during quarter $t$. There are a myriad of ways to summarize trading activity using holdings data. The variables that I use to aggregate trading assign equal weighting to the trades of individual investors following Sias, Starks, and Titman (2001) who use quarterly 13-F holdings data to show that it is actually the number of institutional investors buying and selling that is more reflective of information-based trading than the aggregate number of shares bought and sold. In addition, Chen, Hong, and Stein (2002) show theoretical and empirical support for characterizing or aggregating the opinion of investors according to the breadth of a stock's institutional ownership, as measured by the number of institutional investors holding the stock. ${ }^{9}$

I construct variables summarizing the number of hedge funds in my

\footnotetext{
${ }^{9}$ While I believe my variables construction is well supported, I show (in the Appendix) that my results are robust to alternate holdings-based equal-weighted and value-weighted variables, with different scaling, that summarize trading.
} 
sample that buy and sell each stock $i$ during each quarter $t$ as follows:

$$
\begin{aligned}
\text { HFbuys }_{i, t} & =\sum_{j \in H F \text { sample }} \mathbb{1}_{\text {shares }_{j, i, t} \text {-shares }_{j, i, t-1}>0}, \\
\text { HFsells } & \\
\text { H }_{, t} & =\sum_{j \in H F \text { sample }} \mathbb{1}_{\text {shares }_{j, i, t}-\text { shares }_{j, i, t-1}<0}, \\
\text { HFnet }_{i, t} & =\text { HFbuys }_{i, t}-H \text { Fsell }_{i, t} .
\end{aligned}
$$

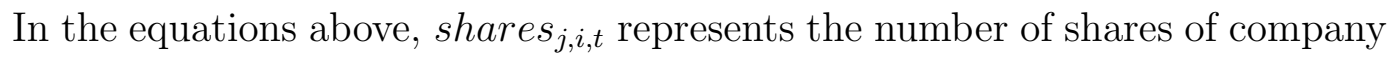
$i$ held by each of the hedge funds in the hedge fund sample (indexed by $j$ ), at the end of quarter $t$. I also calculate similar variables, MFbuys $s_{i, t}, M F$ sell $_{i, t}$, and MFnet $_{i, t}$ to summarize buying and selling among my sample of mutual funds. Table 2 presents summary statistics for the above variables.

For the regressions, I adjust each of the variables shown above by subtracting the rolling 20-quarter moving average, and then dividing this demeaned transformation by the variable's rolling 20-quarter standard deviation. For young stocks with fewer than 20-quarters of history I substitute the stock's entire time-series mean and standard deviation for the rolling 20-quarter variants. I make these adjustments to normalize hedge fund activity across the cross-section of stocks, as well as within each stock through time. For example, an additional 10 hedge funds that buy a small stock in a given quarter might represent a highly abnormal increase in buying, but an additional 10 hedge funds buying a very large stock would not. In addition, the number of individual hedge funds in the hedge fund sample grows by over $25 \%$ over 
the 44-quarter time series of the sample. Therefore, even before considering stock-specific time-series variation, the number of hedge funds that represent an average level of hedge fund buying and selling changes for all stocks over the time series of the sample.

\subsubsection{Variables that Summarize the Direction of Analyst Ratings Change Reports}

I construct variables that summarize the significant information updates among the $k$ sell-side brokerage analysts that cover stock $i$ during quarter $t$. Analysts communicate information by periodically writing research reports about stocks, which are distributed to the brokerage firms' institutional investor clients. I construct my variables using only those analyst research reports that involve a change in the analyst's company-specific buy/sell/hold investment recommendation. Consistent with Womack (1996) and Irvine (2003) I find these analyst ratings change reports coincide with significant abnormal stock price adjustments, which suggests these reports generally contain significant new fundamental information.

I identify the timing and character of individual analyst ratings change reports using the Institutional Brokers Estimate Service (IBES) recommendations detail file. These data contain stock-specific buy/sell/hold recommendations for over 8,000 unique analysts, which I summarize in Table 1. I classify each analyst's ratings change report as an upgrade if the report involves a positive revision to the analyst's rating (i.e. to buy from hold or to 
hold from sell). I classify an analyst's ratings change report as a downgrade if the report involves a negative revision to the analyst's rating. I define the variable Upgrades $_{i, t}$ as the number of upgrade reports published by all covering analysts for company $i$ during quarter $t$. I define Downgrades $i_{i, t}$ as the number of downgrade reports published for company $i$ during quarter $t$. I define NetUpgrades ${ }_{i, t}$ the difference of Upgrades $_{i, t}$ minus Downgrades ${ }_{i, t}$. I also calculate Reports $s_{i, t}$ as the total number of of upgrade and downgrade reports: Upgrades Up $_{i, t}$ plus Downgrades $s_{i, t}$. I present summary statistics for these variables in Table 2 .

For the regressions, I adjust each of the above analyst variables by dividing by the variable's prior period cross-sectional standard deviation among stocks with similar analyst coverage. I make these adjustments to normalize the level of analyst activity across the cross-section of stocks. For example, two upgrade reports in a given quarter for a stock with five covering analysts might represent a very rare event, but two upgrades in a given quarter for a stock with 40 covering analysts might be typical.

I construct Rating $g_{i, t}$ to summarize the average buy/sell/hold recommendation for all covering analysts of stock $i$ as of the end of quarter $t$. To calculate Rating $i_{i, t}$ I calibrate a brokerage firm-specific ratings scales that assign a value of -1 to the lowest within-brokerage firm analyst rating and a value of +1 to the highest within-firm rating. I assign a zero for ratings of hold, equal-weight, neutral, etc. I assign fractional values such as -0.5 and +0.5 
for brokerage firm ratings scales that include intermediate ratings. ${ }^{10}$ For each stock, Rating $_{i, t}$ averages the calibrated $[-1,+1]$ ratings of each of the covering analysts as of the end of quarter $t$. Finally, I calculate Analyst $s_{i, t}$ which is the number of analysts that have at least one previously published recommendation for stock $i$, and whose most recent report for stock $i$ has a revision date later than the end of quarter $t$. I present summary statistics for all analyst variables in Table 2.

\subsubsection{Hedge Fund - Analyst Coverage Overlap}

I borrow from Blocher (2014) to construct Overlap $_{j, i, t}$, which measures the degree to which hedge fund j's portfolio overlaps with the aggregated coverage of all of the analysts covering stock $i$ during quarter $t$. For each stock $i$, I calculate an "analyst coverage portfolio" consisting of the union of the $n$ companies covered by each analyst that covers stock $i$, weighted according to the number of $i$ 's covering analysts who also cover $n$. For example, the "analyst coverage portfolio" for Ford in the last quarter of the time series of the sample consists of 56 companies (the additional companies covered by each of the 19 analysts covering Ford). General Motors is covered by almost all of the 19 analysts that cover Ford, which results in General Motors having the highest weighting in Ford's analyst coverage portfolio.

\footnotetext{
${ }^{10}$ Some brokerage firms allow for five ratings: strong-buy, buy, hold, sell, or strong-sell. Other brokerage firms allow only buy, sell, or hold. My brokerage-specific ratings scale calibration standardizes these different levels of ratings granularity in order to make comparisons between different analysts.
} 
Specifically, for every stock $i$ during quarter $t$, Overlap ${ }_{j, i, t}$ compares the stock's analyst coverage portfolio (with weights $w_{n, t}$ ), with the portfolio of each hedge fund that owns stock $i$ during quarter $t$ (with weights $w_{j, n, t}$ ):

$$
\operatorname{Overlap}_{j, i, t}=\frac{\sum_{n} w_{n, t} * w_{j, n, t}}{\sqrt{\sum_{n} w_{n, t}^{2}} * \sqrt{\sum_{n} w_{j, n, t}^{2}}}
$$

In the equation above I used the trailing 4-quarter average weights when calculating hedge fund weights, $w_{j, n, t}$, for each stock.

\subsubsection{Tercile Sorting Methodology}

Several of my tests involve grouping hedge funds into terciles according to various hedge fund characteristics that include size, turnover, industry specialization, and portfolio overlap with covering analysts. To form hedge fund-size tercile groups, I sort hedge funds every quarter according to the market capitalization of the fund's 13-F holdings, and I form three tercile bins so that each bin has a similar number of individual portfolio positions. I form bins in this manner to ensure a similar amount of aggregate hedge fund buying and selling in each of the hedge fund size bins.

I also sort hedge funds into bins according to portfolio turnover, as defined by portfolio churn rate used in Gaspar, Massa, and Matos (2005), and according to portfolio industry specialization based on the ICI measure defined in Kacperczyk, Sialm, and Zheng (2005). For both turnover and industry concentration, I first sort hedge funds into size quintiles in the manner outlined 
above. Then, within each size quintile, I sort funds into tercile bins. Finally, I also sort hedge funds into tercile bins by Overlap $_{j, i, t}$ for each stock $i$ during quarter $t$. I show summary statistics for hedge fund portfolio size, turnover, and industry concentration in Table 1.

\subsubsection{Control Variables and Panel Characteristics}

I construct several control variables using the Center for Research in Security Prices (CRSP) daily file. I include all stocks with share codes 10 and 11 (common equity) as well as share code 31 (American Depository Receipts). I exclude stocks from CRSP covered by fewer than two analysts, as defined by Analyst $_{i, t}$ above. I also exclude stocks with quarter-end stock prices below $\$ 1$. As shown in Table 2, the resulting panel contains roughly 101,000 firm-quarter observations from 2004-2014 in which all of the holdings, analyst, and control variables are defined. This panel excludes roughly 1,700 low or no coverage stocks in the CRSP cross-section for any given quarter. These excluded low and no coverage stocks generally comprise less than $3 \%$ of aggregate market cap.

I calculate several variables in order to control for observable characteristics of a stock's information environment. These control variables are calculated quarterly but use daily data and include: annualized realized volatility, $\log$ of market cap, and 1- and 4-quarter total return as of the end of quarter $t$. All of my results are robust to winsorizing at $1 \%$ and $99 \%$ levels across the entire sample. 


\subsection{Results}

My tests show that hedge fund trades tend to anticipate analyst reports, while mutual fund trades do not. I also show hedge funds perform best relative to mutual funds among "crowded pools", stocks with high analyst coverage, which supports HST. Finally, I perform tests which reject "tipping" as the sole explanation for my results, and show that individual hedge funds persistently predict the reports of specific analysts, which suggests evidence of private information communications between hedge funds and analysts.

\subsubsection{Are Hedge Funds or Mutual Funds Early-Informed Relative to Analysts?}

In HST, early-informed investors trade aggressively before their private information becomes widely known. I compare the timing of hedge fund and mutual fund private information acquisition (inferred from quarterly trades) to subsequent analyst information acquisition (inferred from upgrade/downgrade reports) using the regressions outlined in Equation (2.5). A null hypothesis in which hedge funds and mutual funds are not informed before analysts would imply both $\beta_{1}$ and $\beta_{2}$ in Equation (2.5) equal zero:

$$
\text { NetUpgrade }_{i, t}=\beta_{1} \text { HFnet }_{i, t-1}+\beta_{2} \text { MFnet }_{i, t-1}+\beta_{3} X_{i, t-1}+\epsilon_{i, t-1} .
$$

However, the positive and highly statistically significant estimates of $\beta_{1}$ for HFnet $_{i, t-1}$ in Table 3 indicate the direction of hedge fund trades in one quarter tends to anticipate the direction of the analyst upgrade or downgrade reports published in the following quarter. I interpret these results as evidence that 
hedge funds are generally informed before analysts. In contrast, the estimates of $\beta_{2}$ for $M F$ net $_{i, t-1}$ in Table 3 are not statistically different from zero, meaning mutual funds not generally informed before analysts.

The point estimates of $\beta_{1}$ are relatively consistent across each Column of Table 3, which indicates that the above results are robust to the inclusion of controls and different fixed-effects. Specifically, Column 3 of Table 3, shows the results of estimating Equation (2.5) with firm fixed-effects, while Columns 4 and 5 include date and dataxindustry fixed-effects. Column 6 shows the results of the Fama-McBeth cross-sectional regression technique outlined in Fama and MacBeth (1973). Taken together, the results in Table 3 suggest that the positive statistical relation between hedge fund trades and subsequent analyst ratings change reports holds within the time-series, the cross-section, and the relatively narrow (4-digit SIC) industry classifications. In addition, the results in Table 3 are robust to error clustering by firm, date, different SIC code granularity, industry $\times \mathrm{SIC}$, and various double-clustering combinations. Clustering by sector, which is the specification that I present in each table, results in the lowest t-statistics.

The significantly negative relation between Rating $_{i, t-1}$ and NetUpgrade ${ }_{i, t}$ in Table 3 reflects the fact that analysts with buy ratings cannot upgrade, and analysts with sell ratings cannot downgrade. Therefore, stocks with high average ratings across covering analysts are mechanically less likely to be upgraded in the subsequent quarter, and vice-versa. Excluding stocks with extreme val- 
ues of Rating $_{i, t-1}$ does not meaningfully alter the results. ${ }^{11}$

\subsubsection{Hedge Funds Predicting Analysts: Estimating Economic Mag- nitudes}

While the regressions presented in Table 3 show a positive statistical relation between the direction of hedge fund trades and the direction of subsequent analyst reports, the scaling of the variables complicates the economic interpretation of the coefficients. To provide a clearer interpretation of the economic magnitude of the extent to which hedge fund trades predict subsequent analyst reports, I estimate a linear probability model (LPM), Poisson, and negative binomial regressions. I then examine subsequent analyst upgrade and analyst downgrade reports separately. These regressions, outlined in Equation (2.6), examine the economic magnitude of the degree to which hedge fund and mutual fund buying and selling (separately) affect the likelihood of subsequent analyst upgrade reports:

$$
\operatorname{Upgr}_{i, t}=\beta_{1} \text { HFbuys }_{i, t-1}+\beta_{2} \text { HFells }_{i, t-1}+\beta_{3} \text { MFbuys }_{i, t-1}+\beta_{4} \text { MFsell }_{i, t-1}+\epsilon_{i, t-1},
$$

The dependent variable, abbreviated as $U p g r_{i, t}$, is the number of analyst upgrade reports for company $i$ published during quarter $i$. The estimate of $\beta_{1}$ from the LPM regression shown in Column 1 of Table 4 indicates that a one standard deviation increase in hedge fund buying increases the probability

\footnotetext{
${ }^{11}$ Extreme values of Rating $g_{i, t-1}$ are either 1, indicating that all covering analysts have buy ratings (and thus no upgrades can occur in the subsequent quarter) or -1 , indicating that all covering analysts have sell ratings (and thus no downgrades can occur). Stock-quarter observations with extreme values of Rating $_{i, t-1}$ account for less than $5 \%$ of the sample.
} 
that an analyst will upgrade in the following quarter by 2.7 percentage points. In addition, the negative estimate of $\beta_{2}$ in Column 1 indicates that, holding the level of hedge fund buying constant, a one standard deviation increase in hedge fund selling decreases the probability that an analyst will upgrade in the following quarter by 1.2 percentage points. The average number of analyst upgrades $\left(U p g r_{i, t}\right)$ across the sample is $55 \%$ (shown in Table 2). Therefore, both hedge fund buying and hedge fund selling have an economically significant bearing on the likelihood of subsequent analyst upgrades.

In contrast, the estimates of $\beta_{3}$ and $\beta_{4}$ presented in Column 1 of Table 4 are not significantly different from one another. ${ }^{12}$ This suggests an economically small and statistically borderline relation in which both increases in mutual fund buying and increases in mutual fund selling, positively predict higher subsequent analyst upgrades. I interpret this as evidence that analysts might pay greater attention to stocks that mutual funds are trading. However, consistent with the results shown in Table 3, the direction of mutual fund trades has no correlation with the direction of subsequent analyst reports.

The dependent variable $U p g r_{i, t}$, the number of analyst upgrades, takes on integer values from 0 to 21, as shown in Table 2. Therefore, in Columns 2 and 3 of Table 4, I show that the results above are robust to estimating Equation (2.6) with count regressions (i.e. Poisson and negative binomial regressions respectively). ${ }^{13}$ The coefficients shown for the count regressions

\footnotetext{
${ }^{12} \mathrm{I}$ use an F-test to examine the difference of the two coefficients: $\beta_{3}-\beta_{4}=0$.

${ }^{13}$ For both count regressions specifications I use the lagged log of the number of analysts
} 
specification in Columns 2 and 3 should be interpreted as incidence ratios. For example, the estimate of $\beta_{1}$ in Column 2 (1.06) indicates that a one standard deviation increase in hedge fund buying suggests that the arrival rate of a subsequent analyst upgrades should change by a factor of 1.06. Multiplying the unconditional $55 \%$ average for $U p g r_{i, t}$ by 1.06 yields an increase of 3.3 percentage points, which is consistent with the estimate of $\beta_{1}$ (2.7 percentage points) from the LPM regression shown in Column 1. The results presented in Column 3, estimating Equation (2.6) using negative binomial regression, are similar. ${ }^{14}$

Columns 4, 5, and 6 of Table 4 present regressions, outlined in Equation (2.7) examine the economic magnitude of the degree to which hedge fund and mutual fund buying and selling (separately) effect the likelihood of subsequent analyst downgrade reports:

$$
\operatorname{Dngr}_{i, t}=\beta_{1} \text { HFbuys }_{i, t-1}+\beta_{2} \text { HFsells }_{i, t-1}+\beta_{3} \text { MFbuys }_{i, t-1}+\beta_{4} M F \text { sells }_{i, t-1}+\epsilon_{i, t-1} .
$$

The estimates of $\beta_{1}$ from the LPM regression shown in Column 4 of Table 4 change sign versus those presented in Column 1, indicating that a one standard deviation increase in hedge fund net buying decreases the probability

covering as an exposure variable. In the LPM specification I include the lagged log of the number of analysts covering as a control variable. Otherwise, the controls, fixed effects, and clustering are similar.

${ }^{14}$ The Akaike information criterion (AIC) is similar between Columns 2 and 3, indicating Poisson and negative binomial regressions have a similar model fit. However, the Bayesian information criterion (BIC) is slightly higher for the negative binomial specification. In addition, Poisson regression assumes that the mean and variance of $U p g r_{i, t}$ are both equal to 1 , which is not the case as shown in Table 2. Negative binomial regressions allows for different mean and variance, suggesting Column 3 might be the most conservative specification for this setting. 
of an analyst downgrade in the following quarter by 1.2 percentage points. In addition, the positive estimate of $\beta_{2}$ in Column 4 indicates that, holding the level of hedge fund buying constant, a one standard deviation increase in hedge fund selling increases the probability that an analyst will downgrade in the following quarter by 2.2 percentage points. The sample average number of analyst upgrades $\left(D n g r_{i, t}\right)$ across the sample is 62\% (shown in Table 2). Therefore, both hedge fund buying and hedge fund selling have an economically significant bearing on the likelihood of subsequent analyst downgrades.

As is the case with Column 1 , the estimates of $\beta_{3}$ and $\beta_{4}$ presented in Column 4 of Table 4 are not significantly different from one another. This suggests that both increases in mutual fund buying, and increases in mutual fund selling, positively predict higher subsequent analyst downgrades. Also consistent with Column 1, I interpret the results of Column 4 for mutual funds as evidence that analysts might pay attention to stocks that mutual funds are trading, but that the direction of mutual fund trades has no correlation with the direction of subsequent analyst reports.

Finally, Columns 5 and 6 of Table 4 show that the above results in Columns 3 are robust to estimating Equation (2.7) with count regressions (Poisson and negative binomial regressions respectively).

\subsubsection{Hedge Fund and Mutual Fund Responses to Analyst Reports}

For my setting HST suggest the way in which hedge funds and mutual funds respond to analyst information can provide additional insight into the se- 
quence of information arrival. In HST, early-informed investors reverse their trades and take profits once their information becomes more widely known and later-informed investors more fully incorporate the information into stock prices through trades. In my setting, I observe the timing of analysts upgrade and downgrade reports. Therefore, HST predicts that the early-informed investors will reverse trades after analysts publish reports. In addition, the trades of early-informed that unwind previous positions will be in the opposite direction as the analyst reports recommend. In contrast, the "sidelined" investors in $\mathrm{CCH}$ respond after signals confirm their information. Therefore, in my setting, "sidelined" investors should trade in a direction is consistent with the recommendations of the analysts.

To discern whether hedge funds more closely resemble the early-informed in HST or the "sidelined" investors in CCH, I use the OLS regressions outlined in Equations (2.8) and (2.9):

$$
\begin{aligned}
& \text { HFnet }_{i, t}=\beta_{1} \text { NetUpgrades }_{i, t-1}+\beta_{2} X_{i, t-1}+\epsilon_{i, t-1} \\
& \text { HFnet }_{i, t}=\beta_{1} \text { Upgrades }_{i, t-1}+\beta_{2} \text { Downgrades }_{i, t-1}+\beta_{3} X_{i, t-1}+\epsilon_{i, t-1}
\end{aligned}
$$

The negative estimate if $\beta_{1}$ in Column 1 of Table 5 indicates a negative relation between the net direction of analyst ratings change reports, and the net direction of hedge fund trades in the next quarter. The negative estimate of $\beta_{1}$ in Column 2 indicates that, holding the number of downgrade reports constant, the number of upgrade reports negatively correlates with the net direction of subsequent hedge fund trades. These results suggest that, in response to 
analyst upgrades, hedge funds buy less and/or sell more. These patterns are consistent with the early-informed investors in HST.

I examine mutual fund trades in reaction to analyst information with the OLS regressions outlined in Equations (2.10) and (2.11):

$$
\begin{aligned}
& \text { MFnet }_{i, t}=\beta_{1} \text { NetUpgrades }_{i, t-1}+\beta_{2} X_{i, t-1}+\epsilon_{i, t-1} \\
& \text { MFnet }_{i, t}=\beta_{1} \text { Upgrades }_{i, t-1}+\beta_{2} \text { Downgrades }_{i, t-1}+\beta_{3} X_{i, t-1}+\epsilon_{i, t-1}
\end{aligned}
$$

Columns 3 and 4 of Table 5 indicate that mutual funds react to analyst information in exactly the opposite manner as hedge funds. Specifically, the positive estimate of $\beta_{1}$ presented in Column 3 of Table 5 indicates a positive relation between the net direction of the analyst reports and the net direction of mutual fund trades in the next quarter. These results are supported by the positive estimate of $\beta_{1}$ and the negative estimate of $\beta_{2}$ presented in Column 4 . These results suggest that, after upgrade reports, mutual funds tend to buy more and/or sell less, and after downgrade reports mutual funds tend to buy less and/or sell more.

I interpret these patterns as evidence that mutual funds are not earlyinformed relative to analysts. In fact, mutual funds appear to incorporate analyst ratings change report information into subsequent trades, and with a significant lag. The trading patterns I find for mutual funds align more closely with the "sidelined" investors in $\mathrm{CCH}$. In addition, the trading patterns for mutual funds shown in Table 5 support similar findings in Kacperczyk and Seru (2007), Busse, Green, and Jegadeesh (2012), and Brown, Wei, and Wermers 
(2013). However, I believe my findings, that hedge funds react differently than mutual funds to analyst reports, are new.

\subsubsection{Hedge Fund Performance and Analyst Coverage}

The results presented in Tables $3-5$ suggest that hedge funds tend to acquire information before analysts, and then reverse trades after analysts publish upgrade or downgrade reports that subsequently make information more widely known. These patterns suggest that the information contained in analyst reports, and the stock price adjustments in reaction to this information, generally helps early-informed hedge funds exploit information acquisition advantages. This intuition is consistent with the HST prediction that investors who expect to be early-informed ex ante prefer to investigate large and wellknown stocks where a "crowded pool" of slower, uninformed investors will provide liquidity when the early-informed exit their positions.

In contrast to hedge funds, Bennett, Sias, and Starks (2003) show that over time mutual funds have shown an increased preference for "greener pastures", i.e. smaller and less well known stocks. Opportunities for investors to profit from information are most prevalent among these smaller, low analyst coverage stocks, as shown in Hong, Lim, and Stein (2000).

I examine hedge funds and mutual fund preferences for "crowded pool" and "greener pastures" by examining the weighted performance of hedge funds and mutual funds among different stocks, using the regression outlined in Equation (2.12). In these regressions the dependent variable $\operatorname{Per} f_{f, t}$ is the 
quarterly weighted average performance for mutual funds and hedge funds: ${ }^{15}$

$$
\operatorname{Perf}_{f, t}=\alpha+\beta_{1} H F_{f}+\Gamma_{t}+\epsilon_{f, t}
$$

The estimate of the constant in Column 1 of Table 6 indicates that the weighted average quarterly performance for my sample of mutual funds averaged $2.49 \%$ over the 44-quarter time series of my sample. The positive and significant estimate of $\beta_{1}(0.55 \%)$ indicates that hedge funds outperformed mutual funds by an average of 55 bps per quarter over this period. ${ }^{16}$

However, the estimate of $\beta_{1}$ in the tercile sort columns in Table 6 indicate that hedge funds outperform mutual funds by an economic and statistically significant extent only among the largest market-cap stocks. The last column of Table 6 indicates that hedge fund outperformance among large stocks is statistically different than hedge fund outperformance among small stocks. I interpret this result as supporting the HST "crowded pools" prediction. By contrast, mutual fund performance, as measured by the estimate of the constant, is highest among the smallest stocks. I interpret this result as supportive of the preference for "greener pastures" shown in Bennett, Sias, and Starks (2003).

Similarly, the estimates of $\beta_{1}$ in the tercile sort columns of Table 7 in-

\footnotetext{
${ }^{15}$ The subscript $f$ is a binary indicator for either mutual funds or hedge funds.

${ }^{16}$ These results are consistent with Griffin and Xu (2009) who calculate returns using 13-F holdings data for a sample of hedge funds and mutual funds in a similar manner. They find that hedge funds outperform mutual funds by $2.35 \%$ per year from 1995-2004. I find a higher statistical significance, which may reflect my larger sample of hedge funds, and my slightly longer and more recent time-series.
} 
dicate that hedge funds outperform mutual funds by an economic and statistically significant extent only among the highest coverage stocks, after adjusting for size. The last column of Table 7 indicates that hedge fund outperformance among high analyst coverage stocks is statistically different than hedge fund outperformance among low analyst coverage stocks. I interpret these results as also supportive of a hedge fund preference for "crowded pools."

To further examine "crowded pools" with respect to hedge funds I examine the degree to which hedge fund trades predict analyst reports among stocks with different levels of analyst coverage. Column 1 of Table 8 shows the results from running a regression similar to Equation (2.5), but excluding mutual fund trades from the independent variables in the regression:

$$
\text { NetUpgrade }_{i, t}=\beta_{1} \text { HFnet }_{i, t-1}+\beta_{2} X_{i, t-1}+\epsilon_{i, t-1} \text {. }
$$

However, the remaining columns of Table 8 show the results from running Equation (2.13) for stocks sorted according to the number of analysts covering. Columns 2-5 of Table 8 show that the size and statistical significance of $\beta_{1}$ increases monotonically with the number of analysts covering. This suggests that hedge fund trades most strongly predict analysts among stocks with high analyst coverage. These results support, and possibly explain, the results presented in Table 7 which show that hedge funds outperform mutual funds most strongly among stocks with high analyst coverage. ${ }^{17}$

\footnotetext{
${ }^{17}$ These results complement Agarwal et al. (2013) which shows that hedge funds lobby the SEC to hide the portfolio positions of small, low analyst coverage stocks from 13-F filings in order to initiate portfolio positions.
} 


\subsubsection{Analysts "Tipping" Hedge Funds}

This section examines an explanation for how hedge funds become early-informed relative to analysts. I first examine the possibility that hedge fund trades predict the direction of subsequent analyst upgrade and downgrade reports as a result of analyst "tipping." This practice, first examined in Irvine, Lipson, and Puckett (2007), involves analysts privately "tipping off" certain favored investors immediately before publishing important research reports. I exploit variation in the intra-quarter timing of analyst reports to examine the extent to which analysts favoring hedge funds with "tips" explains the positive relation I find between hedge fund trades and subsequent analyst reports.

Both Klein, Saunders, and Wong (2014) and Kadan, Michaely, and Moulton (2014) show that "tipped" investor trades occur in a 1-5 day window immediately before analyst reports are published. These results suggest that the value of analyst "tips" depreciates rapidly, and/or that investors wait to trade on analyst tips until immediately before the "tipping" analyst publishes the report. Therefore, in my setting, the trades of "tipped" hedge funds in one quarter should strongly predict the direction of analyst upgrade and downgrade reports published at the very beginning of the following quarter. However, "tipped" trades in one quarter should not predict analyst reports published later into the following quarter.

Panel A of Figure 2.1 shows the frequency of analyst reports published according to the intra-quarter day of the report's publication date. If analyst "tips" explain my results, I should find that hedge fund trades in one quarter 
positively correlate with the direction of only those analyst reports made in the very beginning of the following quarter. Table 9 shows the results from regressions that test how hedge fund trades predict the direction of subsequent analyst reports grouped by the intra-quarter month timing of the analyst reports: Equations (2.14)-(2.16) examine hedge fund trades relative to analyst reports published in each of three intra quarter months of the following quarter separately:

$$
\begin{aligned}
& \text { 1st Month NetUpgrade }{ }_{i, m 1 \in[t]}=\beta_{1} \text { HFnet }_{i, t-1}+\beta_{2} X_{i, t-1}+\epsilon_{i, t-1} \text {, } \\
& \text { 2nd Month NetUpgrade } i_{i, m 2 \in[t]}=\beta_{1} \text { HFnet }_{i, t-1}+\beta_{2} X_{i, t-1}+\epsilon_{i, t-1} \text {, } \\
& \text { 3rd Month NetUpgrade } e_{i, m 3 \in[t]}=\beta_{1} \text { HFnet }_{i, t-1}+\beta_{2} X_{i, t-1}+\epsilon_{i, t-1} \text {, }
\end{aligned}
$$

The positive and significant estimate of $\beta_{1}$ in Column 1 of Table 9 indicates a positive relation between the trades of hedge funds in one quarter and the direction of analyst upgrade and downgrade reports published in the following quarter, which is consistent with the results shown in Table 3. In addition, the positive and significant estimates of $\beta_{1}$ in Columns 2, 3, and 4 indicate positive relations between the trades of hedge funds in one quarter, and the direction of analyst upgrade and downgrade reports published in each of the first, second, and third months of the following quarter.

Tipping may, in whole or in part, explain how hedge fund trades anticipate analyst reports published very early in the subsequent quarter, as shown in Column 2 of Table 9. However, it is highly unlikely that tipping explains how hedge fund trades in one quarter positively correlate with the direction of 
analyst reports published in more than one or two months into the following quarter, as shown in Columns 3 and 4 of Table 9.

Panel B of Figure 2.1 shows the frequency of analyst reports published according to the day of the report's publication date relative to the day of the company's quarterly earnings release. The dramatic spike in analyst report frequency coinciding with company earnings dates shown in Panel B illustrates the degree to which information from earnings releases dictate hedge fund upgrade and downgrade reports. I examine how hedge fund trades in one quarter positively correlate with the direction of analyst reports made before, during, and after company earnings as an additional examination of analyst "tipping" explains, as well as an examination of whether hedge fund trades predict analyst reports containing a higher degree of "soft" information (i.e. information resulting from analyst-specific information acquisition processes) relative to reports containing a higher degree of commonly revealed information, such as information from corporate earnings releases.

Table 10 shows the results from regressions testing how hedge fund trades predict the direction of subsequent analyst reports grouped according to the timing of the analyst report relative to the earnings release date. Equations (2.17)-(2.19) examine hedge fund trades relative to analyst reports published 
before earnings, during earnings, and after earnings separately:

$$
\begin{aligned}
& \text { Pre-Earnings NetUpgrade } \text { N }_{i, t}=\beta_{1} \text { HFnet }_{i, t-1}+\beta_{2} X_{i, t-1}+\epsilon_{i, t-1} \text {, } \\
& \text { During Earnings NetUpgrade } \text { Ni,t }=\beta_{1} \text { HFnet }_{i, t-1}+\beta_{2} X_{i, t-1}+\epsilon_{i, t-1} \text {, } \\
& \text { Post Earnings NetUpgrade }_{i, t}=\beta_{1} \text { HFnet }_{i, t-1}+\beta_{2} X_{i, t-1}+\epsilon_{i, t-1} \text {, }
\end{aligned}
$$

The positive and significant estimates of $\beta_{1}$ in Columns 2, 3, and 4 indicate positive relations between the trades of hedge funds in one quarter, and the direction of analyst upgrade and downgrade reports before, during, and after earnings are reported in the following quarter.

The results shown in Tables 9 and 10 suggest that hedge fund trades predict analyst reports made throughout the subsequent quarter, and that hedge fund trades predict analyst reports relating to different types of information. These results provide additional evidence that analyst "tipping" cannot explain the entirely of how hedge fund trades in one quarter positively correlate with the direction of analyst reports published in the following quarter. In addition, the results of Tables 9 and 10 address another alternative explanation for the positive relation between hedge fund trades and the direction of subsequent analyst upgrade and downgrade reports: analysts may "copycat" hedge fund information by reading the hedge fund's 13-F disclosures. Hedge funds must file 13-F disclosures with the SEC within 45 days of the quarter-end, and Brown and Schwarz (2011) show that hedge funds file 13-Fs on average 40 days into the following quarter. Therefore, analyst reports published more than 40 days into the quarter might be informed by, 
or influenced by, or completely "copycatting" hedge fund information.

\subsubsection{Which Hedge Funds Best Anticipate Analysts?}

In this section, I investigate a hypothesis in which hedge funds acquire information, make trades, and then pro-actively disclose their information to analysts through private communications. By strategically disclosing information to analysts, hedge funds expect that analysts publish their information in research reports, and accelerate the incorporation of their information into stock prices. Such actions would be consistent with the preferences of the early-informed in HST, who, after making trades, prefer that their information become widely known as quickly as possible. Analyst information acquisition processes are an important topic in the extensive analyst literature. $^{18}$ However, analysts learning about companies from investors has not been extensively examined.

To examine strategic disclosures I dis-aggregate the holdings data for hedge funds, and group the hedge funds into terciles according to characteristics that I associate with a propensity for predicting analysts. I hypothesize that the largest hedge funds can most successfully influence analysts, due to the fact that important brokerage clients have the greatest access to private communications with analysts. I also hypothesize that, within size groupings, the hedge funds with the highest turnover would be most likely to engage in

\footnotetext{
${ }^{18}$ See Ramnath, Rock, and Shane (2008) for an extensive review of over 250 papers examining analysts.
} 
strategic information disclosures, because hedge funds that implement highturnover strategies more urgently prefer that their information is incorporated into prices quickly. I hypothesize that hedge funds with high industry concentration will have the most valuable information to reveal to analysts. Finally, I propose that hedge funds with portfolios that closely overlap with covering analysts are most likely to have relationships with covering analysts, and engage in private communications.

I test these four strategic disclosure related hypotheses by sorting hedge funds into terciles by size, portfolio turnover, industry concentration, and the degree to which their portfolios overlap with covering analysts (as discussed in Section 2.2.6 above). I then compare the extent to which the trades of each group of hedge funds anticipates the direction of subsequent analyst upgrade and downgrade reports. Table 1 shows averages for each of the hedge fund tercile groups, and Table 11 shows the results of hedge fund tercile regressions of the form:

$$
\text { NetUpgrade }_{i, t}=\beta_{1} \text { HFnet-T } 1_{i, t-1}+\beta_{2} \text { HFnet-T2 } 2_{i, t-1}+\beta_{3} \text { HFnet-T } 3_{i, t-1}+\epsilon_{i, t-1} \text {. }
$$

Column 1 of Table 11 shows the results of sorting hedge funds into terciles according to the aggregate market cap of their holdings. The coefficients for the three terciles increase monotonically according to hedge fund size, and $\beta_{3}$ is statistically significantly different than $\beta_{1}$. This indicates the trades of the largest hedge funds more strongly predict the direction of subsequent analyst reports than the trades of the smallest hedge funds, which is consistent with 
the strategic information disclosure hypothesis outlined above.

In addition, the results shown in Column 2 of Table 11 show that the trades of high turnover hedge funds more strongly predict subsequent analyst reports than the trades of median turnover and low turnover hedge funds. Column 3 shows that the trades of the hedge funds with the highest industry concentration most strongly predict the direction of subsequent analyst reports. This columns also shows that the trades of low industry concentrated hedge funds do not predict subsequent analyst reports. All of these results are consistent with the strategic information disclosures hypothesis.

Finally, the results shown in Column 4 of Table 11 show that the trades of hedge funds with portfolios that overlap most closely with the union of the combined coverage of all covering analysts most strongly predict subsequent analyst upgrade and downgrade reports. By contrast, the trades of hedge funds that have the lowest portfolio overlap with covering analysts do not predict the direction of subsequent analyst reports. I define my measure of hedge fund portfolio overlap with covering analysts, Overlap ${ }_{j, i, t}$, in detail in Section 2.2.5 above. This measure attempts to capture the degree to which each hedge fund portfolio overlaps with the analysts covering each stock. The concentration of the relation between hedge fund trades and subsequent analyst reports among high-overlap hedge funds is also consistent with the strategic information disclosures hypothesis.

These tests, when taken in isolation, cannot reject the null hypothesis that hedge funds predict subsequent analyst reports as a result of arriving at 
information completely independently. For example, it is possible that larger hedge funds have greater resources to deploy for quickly acquiring information than smaller hedge funds. It is also possible that high turnover hedge funds deploy greater resources in gathering information quickly. However, taken together, I believe these results broadly support the strategic disclosure hypothesis. I further dis-aggregate the hedge fund and analyst data to explore this hypothesis below.

\subsubsection{Do Individual Hedge Funds Persistently Predict Individual Analysts?}

In this section, I investigate private strategic disclosures of information by hedge funds as an explanation for how hedge fund trades predict the direction of subsequent analyst reports by further dis-aggregating both the hedge funds holdings data and the analysts data. I hypothesize that private communications between hedge funds and analysts arise from durable relationships between hedge fund managers and research analysts. These relationships should manifest in the data as a persistence in the extent to which the trades of individual hedge funds predict reports of individual analysts.

In order to empirically test for persistence of the extent to which individual hedge funds trades predict reports of individual analysts I group analysts by brokerage firm, and I divide the sample period for each hedge fund into two equal periods: $t-1$ for the first half, and $t+1$ for the second half ( $t=0$ is the mid-point). My tests for persistence relate the extent to which 
hedge funds predict analysts in the second half of the sample, to the extent to which the same hedge funds predicted the same analysts in the first half of the sample. These tests aim to reject a null hypothesis of zero persistence.

Specifically, I run the following regression for each of the 44,850 pairscombinations of hedge fund $j$ and brokerage firm $k$ for the quarters in the first half of the sample (period $t-1$ ) for each hedge fund $j$ :

$$
\text { NetUpgrade }_{k, i, t}=\beta_{1} \text { HFnet }_{j, i, t-1}+\beta_{2} \text { Rating }_{k, i, t-1}+\epsilon_{i, t-1} \text {. }
$$

In the above $N e t \operatorname{Ppgrade}_{k, i, t}$ and Rating $_{k, i, t-1}$ relate only to the ratings change reports and ratings of the analysts working at brokerage firm $k$ for stocks $i$ under coverage. ${ }^{19}$ In addition, F net $_{j, i, t-1}$ only relates to the trades of only hedge fund $j$. For these regressions I include only the 604 hedge funds in the data for at least 24 quarters, and only analysts from those 98 brokerage firms in the data for at least 36 quarters. $^{20}$ There are 44,850 combinations in which the positions of the hedge funds overlaps with the coverage of the brokerage firm's analysts. ${ }^{21}$

I use the results from the regressions outlined in Equation (2.21) to define the variable Predict $_{j, k, t-1}$ which is an indicator equal to one if the

\footnotetext{
${ }^{19}$ To exclude "tipping" I only include ratings change reports published more than 1 week into each quarter.

${ }^{20} \mathrm{I}$ also require that each brokerage firm covers at least 5 stocks each quarter. This results in several very small one- and two- analysts brokerage firms being dropped from this analysis.

${ }^{21}$ I run the regression outlined in Equation (2.21) for only when the positions of the hedge fund $j$ overlap with the coverage of the analysts at brokerage firm $k$ over the course of the quarters in period $t-1$. On average, each hedge fund overlaps with analysts at 74 unique brokerage firms.
} 
coefficient $\beta_{1}$ from Equation (2.21) is positive with a t-statistic greater than 1.8. The average for Predict Pr,k-1 $_{j, 1}$ is $4.6 \%$ across the 604 hedge funds. This suggests that, on average, the trades of each hedge fund strongly predict the direction of the reports from analysts at only 3 or 4 unique brokerage firms. I also define AvgPredict ${ }_{j, t-1}$ which averages Predict $_{j, k, t-1}$ for each hedge fund $j$. This reflects the ability of each hedge fund $j$ to predict analysts generally in the first half of each sample.

I perform the regressions outlined in Equation (2.21) using the second half of of each hedge fund sample (period $t+1$ ) to define the variable Predict $_{j, k, t+1}$ for each of the $44,850 j \times k$ pairs. The result is 44,850 pairs of Predict $_{j, k, t-1}$ which indicates how each fund predicts each analysts in the first half of the sample, and Predict $_{j, k, t+1}$ which indicates prediction in the second half of the sample. I then relate these two variables using the below regressions:

$$
\begin{aligned}
& \text { Predict }_{j, k, t+1}=\beta_{1} \text { Predict }_{j, k, t-1}+\epsilon_{j, k, t-1}, \\
& \text { Predict }_{j, k, t+1}=\beta_{1} \text { Predict }_{j, k, t-1}+\beta_{2} X_{j, t-1}+\Gamma_{k}+\epsilon_{j, k, t-1}, \\
& \text { Predict }_{j, k, t+1}=\beta_{1} \text { Predict }_{j, k, t-1}+\beta_{2} X_{k, t-1}+\lambda_{j}+\epsilon_{j, k, t-1} .
\end{aligned}
$$

The results shown in Column 1 of Table 12 corresponds to Equation (2.22), which is a simple pooled OLS specification. The estimate for $\beta_{1}$ indicates that an individual hedge fund is 1.52 percentage points more likely to predict analysts at a specific brokerage firm in the second period if the hedge fund predicted the same analysts in the first period. This represents a marginal 
increase of over $30 \%$ relative to an unconditional likelihood of $4.87 \%$.

The results in Columns 2 and 3 of Table 12 corresponds with the regressions in Equation (2.23), which includes a fixed effect for every unique brokerage firm $\left(\Gamma_{k}\right)$ and hedge fund controls variables. The estimate for Overlap $_{j, k, t-1}$ in Column 3 indicates that high overlap between hedge fund positions and analyst coverage is associated with hedge fund $\times$ analyst pre-

diction. The estimate of IndConcentr $_{j, t=0}$ indicates that hedge fund portfolio industry concentration is associated with hedge fund $\times$ analyst prediction. These results support those shown in Table 11 above for the trades of aggregated hedge funds. Finally, the estimate for AvgPredict $_{j, t-1}$ indicates that hedge fund ability to predict all analysts generally is persistent. However, the statistical and economic significance of idiosyncratic persistence, as measured by Predict $_{j, k, t-1}$ is generally robust to the inclusion of AvgPredict $_{j, t-1}$ to the regression.

The results in Columns 4 and 5 of Table 12 corresponds with the regressions in Equation (2.24), which includes a fixed effect for every unique hedge fund $\left(\lambda_{j}\right)$ and brokerage firm controls variables. These results are an additional illustration of the robustness of the degree to which idiosyncratic persistence in the first period persists in the second period.

\subsection{Conclusion}

I document trading patterns indicating that hedge funds tend to get information first, then analysts, and finally mutual funds. In addition, de- 
spite competing in the information arena, I show that hedge funds tend to benefit from the presence of both analysts and mutual funds. The presence of mutual funds and analysts allows hedge funds to trade more aggressively and exit positions more quickly when the information is incorporated into prices. This process helps explain how hedge funds generate risk adjusted returns. Specifically, despite the advantages in investing in small stocks with low analyst coverage, where competition is less intense and opportunities for trading anomalies are more common, my evidence indicates hedge funds most dramatically outperform mutual funds when trading large stocks with high analyst coverage. ${ }^{22}$ This evidence is consistent with HST, which illustrates that the early-informed investors have the greatest advantages when the trading in "crowded pools."

Finally, the benefit to a hedge fund of a public signal that confirms, with a lag, their private information suggests that hedge funds have an incentive to feed information to the analysts. ${ }^{23}$ My results are consistent with hedge funds strategically communicating of information to analysts. I believe additional examinations into the private information networks between hedge funds, mutual funds, and analysts are a promising area for future research.

\footnotetext{
${ }^{22}$ Hong, Lim, and Stein (2000) show that, consistent with slower information diffusion, momentum strategies are most profitable among small, and (holding size constant) low analyst coverage stocks.

${ }^{23}$ Ljungqvist and Qian (2014) examine hedge funds that disclose their information directly to the public.
} 


\section{Figure 2.1: Timing of Analyst Reports}

This figure presents the aggregated daily frequency of analyst upgrade and downgrade reports. Panel A presents the report frequency according to the calendar day of the quarter in which each report is published. Panel B presents report frequency each day relative to the company's quarterly earnings release. I classify earnings season reports as those published within three trading days of the earnings release date. The data include quarters from 2004-2014.

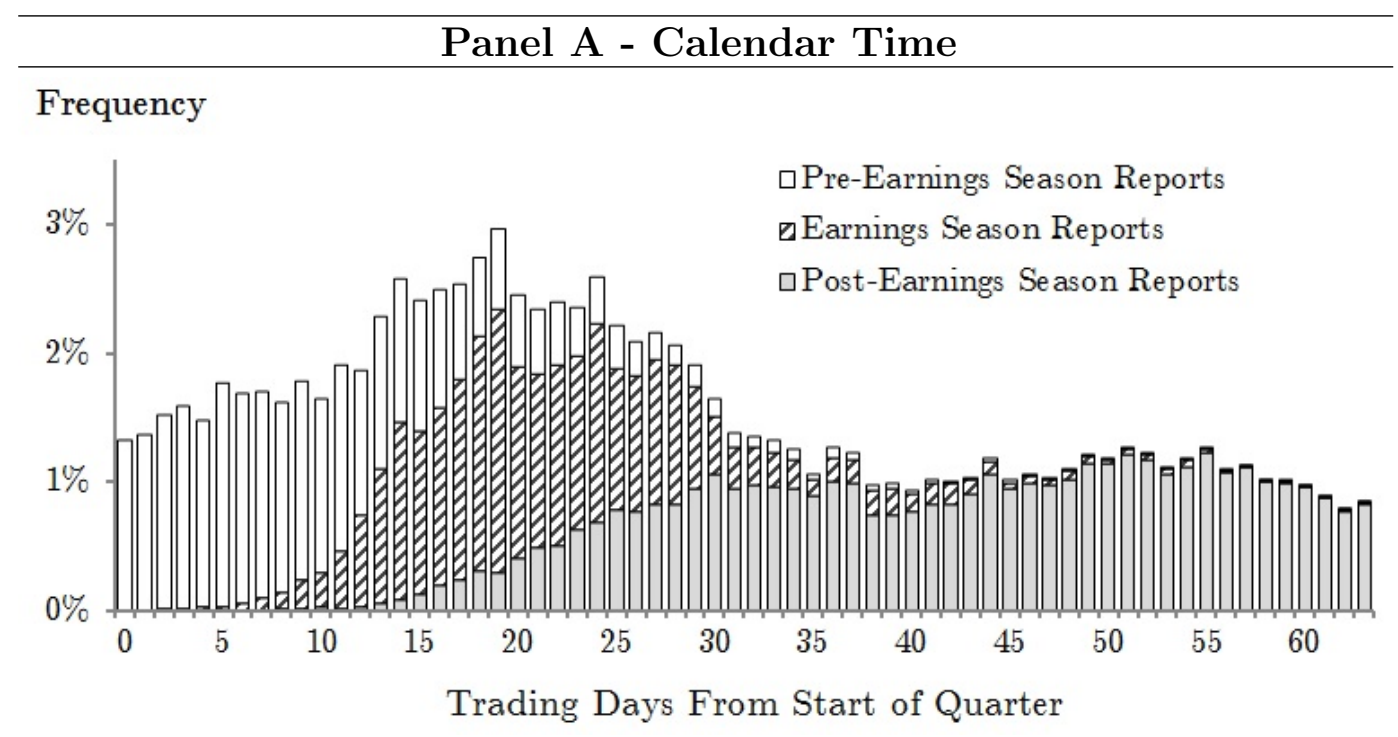

\section{Panel B - Event Time}

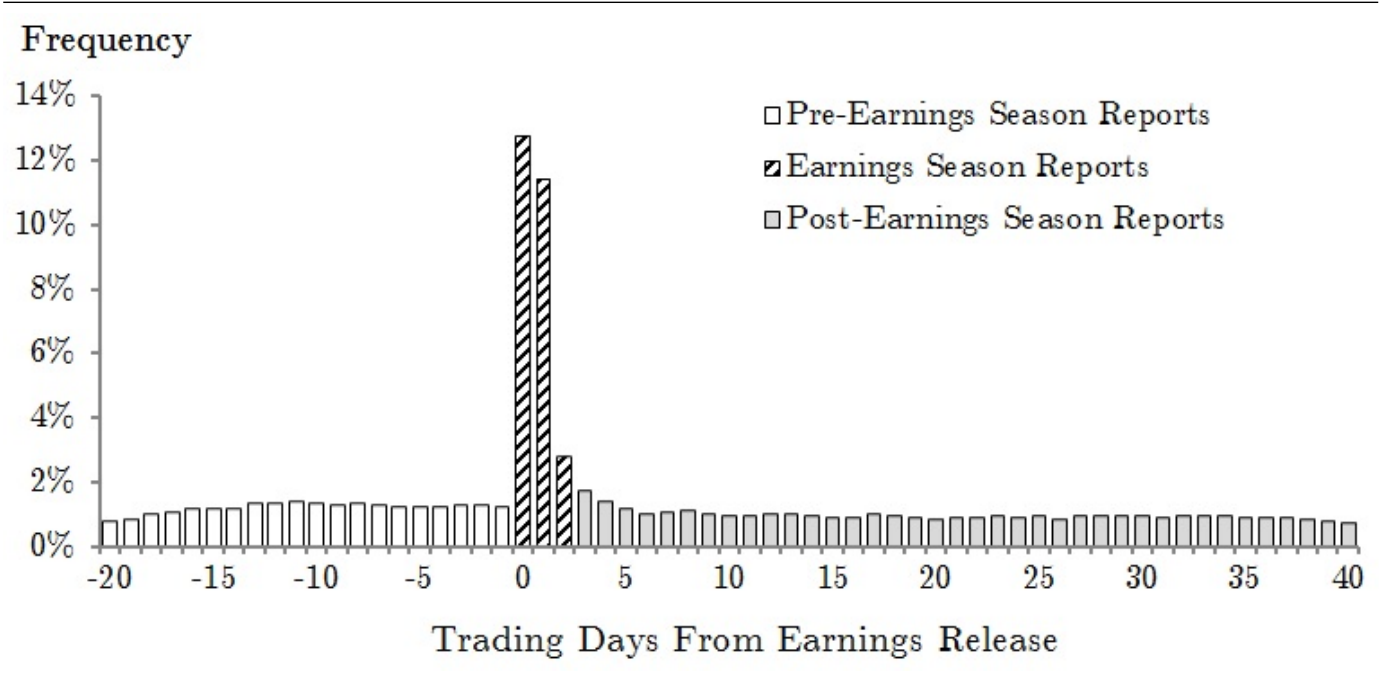


Table 1: Hedge Fund, Mutual Fund, and Analyst Summary Statistics

This table presents summary statistics for the hedge funds, mutual funds, and analysts used to calculate the quarterly stock-level variables presented in Table 2. I describe the selection of the hedge fund and mutual fund samples in Sections 2.2.1 and 2.2.2. I describe the analyst data in Section 2.2.4. The summary statistics presented below reflect averages for each fund, brokerage firm, and analyst over the time-series of the sample. The data are quarterly from 2004-2014.

\begin{tabular}{|c|c|c|c|c|c|c|}
\hline & Mean & Median & Std Dev & Min & $\operatorname{Max}$ & $\mathrm{n}$ \\
\hline \multicolumn{7}{|l|}{ Hedge Funds } \\
\hline Portfolio Size & $\$ 666$ & $\$ 209$ & $\$ 1,653$ & $\$ 0.1$ & $\$ 27,593$ & 1,436 \\
\hline Number of Pos & 82 & 33 & 183 & 1 & 2,420 & 1,436 \\
\hline Turnover & $25 \%$ & $24 \%$ & $15 \%$ & $0 \%$ & $89 \%$ & 1,436 \\
\hline Ind Concentration & 0.20 & 0.13 & 0.19 & 0.00 & 1.14 & 1,436 \\
\hline \multicolumn{7}{|l|}{ Mutual Funds } \\
\hline Portfolio Size & $\$ 1,168$ & $\$ 234$ & $\$ 4,025$ & $\$ 0.01$ & $\$ 90,769$ & 2,053 \\
\hline Number of Pos & 101 & 65 & 154 & 1 & 2,578 & 2,053 \\
\hline Turnover & $13 \%$ & $12 \%$ & $7 \%$ & $0 \%$ & $48 \%$ & 2,053 \\
\hline Ind Concentration & 0.12 & 0.05 & 0.20 & 0.00 & 1.10 & 2,053 \\
\hline \multicolumn{7}{|l|}{ Brokerage Firms } \\
\hline Number of Analysts & 9 & 3 & 21 & 1 & 224 & 548 \\
\hline Ind Concentration & 0.48 & 0.45 & 0.28 & 0.00 & 1.13 & 548 \\
\hline \multicolumn{7}{|l|}{ Analysts } \\
\hline Companies Covered & 7 & 5 & 6 & 1 & 64 & 8,311 \\
\hline
\end{tabular}




\section{Table 2: Regressions Variables Summary Statistics}

This table presents summary statistics for variables used in the regressions presented below. The hedge fund, mutual fund, and analyst variables are aggregated from the hedge fund, mutual fund, and analyst samples summarized in Table 1. The construction of each of the variables below are described in Sections 2.2.3 and 2.2.4. The data are quarterly from 2004-2014 and include companies with at least two analysts covering.

\begin{tabular}{llllll}
\hline \hline & Mean & Median Std Dev & Min & Max & $n$ \\
\hline
\end{tabular}

\section{Hedge Fund Variables}

HFnet $_{i, t}$

HFbuys $_{i, t}$

HFsells $_{i, t}$

HFholders $i, t$

$\begin{array}{llllll}(0.0) & 0.0 & 7.7 & (137) & 130 & 101,265 \\ 12.7 & 10.0 & 10.9 & 0 & 178 & 101,265 \\ 12.7 & 10.0 & 11.0 & 0 & 168 & 101,265 \\ 21.7 & 17.0 & 18.7 & 0 & 255 & 101,265\end{array}$

Mutual Fund Variables

MFnet $_{i, t}$

MFbuys $_{i, t}$

MFsells $_{i, t}$

MFholders $_{i, t}$

\section{Analyst Variables}

NetUpgrades $_{i, t}$

Upgrades $_{i, t}$

Downgrades $_{i, t}$

Reports $_{i, t}$

Analysts $_{i, t}$

Rating $_{i, t}$

\section{Other Variables}

Size $_{i, t}$

$\begin{array}{llllll}(1.9) & (1.0) & 14.9 & (324) & 521 & 101,265 \\ 20.4 & 13.0 & 24.4 & 0 & 558 & 101,265 \\ 22.3 & 14.0 & 27.7 & 0 & 369 & 101,265 \\ 56.7 & 37.0 & 66.8 & 0 & 867 & 101,265\end{array}$

$\begin{array}{llllll}(0.06) & 0.0 & 1.2 & (20) & 11 & 101,265 \\ 0.55 & 0.0 & 0.9 & 0 & 15 & 101,265 \\ 0.62 & 0.0 & 1.1 & 0 & 21 & 101,265 \\ 1.17 & 1.0 & 1.6 & 0 & 29 & 101,265 \\ 10.8 & 9.0 & 7.5 & 0 & 61 & 101,265 \\ 0.4 & 0.4 & 0.3 & (1) & 1 & 101,265\end{array}$

$\begin{array}{llllll}\$ 6.3 & \$ 1.2 & \$ 21.9 & \$ 0.0 & \$ 647.4 & 101,265\end{array}$




\section{Table 3: Investor Trades Before Analyst Reports}

This table presents OLS regressions relating quarterly hedge fund net buying to the direction of analyst ratings change reports in the next quarter. The dependent variable is $N e t U p g r_{i, t}$, which is the number of analyst upgrade reports minus the number of analyst downgrade reports. The independent variables of interest are $H F$ net $_{i, t-1}$, which is the number of hedge funds buying minus the number of hedge funds selling stock $i$ during quarter $t-1$, and MFnet $_{i, t-1}$ which is a similar measure for mutual funds. These variables are de-meaned and scaled by standard deviation, as described in the Data section. Observations are stock-quarter from 2004-2014. T-statistics are presented in parentheses: $* * *$ indicates significance at $1 \%$ level, ${ }^{* *}$ indicates $5 \%$, and $*$ indicates $10 \%$.

\begin{tabular}{|c|c|c|c|c|c|c|}
\hline & $\begin{array}{c}(1) \\
\text { NetUpgr } \\
\text { i,t }\end{array}$ & $\begin{array}{c}(2) \\
\text { NetUpgr } r_{i, t}\end{array}$ & $\begin{array}{c}(3) \\
\text { NetUpgr } \\
, t\end{array}$ & $\begin{array}{c}(4) \\
\text { NetUpgr } \\
\text { i,t }\end{array}$ & $\begin{array}{c}(5) \\
\text { NetUpgr } \\
, t\end{array}$ & $\begin{array}{c}(6) \\
\text { NetUpgr } r_{i, t}\end{array}$ \\
\hline HFnet $_{i, t-1}$ & $\begin{array}{l}4.55^{* * *} \\
(9.44)\end{array}$ & $\begin{array}{l}3.92^{* * *} \\
(8.78)\end{array}$ & $\begin{array}{l}3.72^{* * *} \\
(8.36)\end{array}$ & $\begin{array}{l}3.78^{* * *} \\
(8.69)\end{array}$ & $\begin{array}{l}3.56^{* * *} \\
(7.27)\end{array}$ & $\begin{array}{l}4.28^{* * *} \\
(8.84)\end{array}$ \\
\hline MFnet $_{i, t-1}$ & $\begin{array}{l}-0.12 \\
(-0.40)\end{array}$ & $\begin{array}{l}-0.46 \\
(-1.39)\end{array}$ & $\begin{array}{l}-0.09 \\
(-0.24)\end{array}$ & $\begin{array}{l}-0.04 \\
(-0.14)\end{array}$ & $\begin{array}{l}0.05 \\
(0.14)\end{array}$ & $\begin{array}{l}-0.15 \\
(-0.59)\end{array}$ \\
\hline HFnet $_{i, t-2}$ & & $\begin{array}{l}1.33^{* * *} \\
(4.17)\end{array}$ & $\begin{array}{l}1.47^{* * *} \\
(4.71)\end{array}$ & $\begin{array}{l}1.59^{* * *} \\
(5.02)\end{array}$ & $\begin{array}{l}1.29^{* * *} \\
(3.41)\end{array}$ & $\begin{array}{l}1.88^{* *} \\
(5.63)\end{array}$ \\
\hline MFnet $_{i, t-2}$ & & $\begin{array}{l}-0.19 \\
(-0.74)\end{array}$ & $\begin{array}{l}0.27 \\
(1.06)\end{array}$ & $\begin{array}{l}0.14 \\
(0.58)\end{array}$ & $\begin{array}{l}-0.29 \\
(-0.98)\end{array}$ & $\begin{array}{l}0.24 \\
(0.79)\end{array}$ \\
\hline Rating $_{i, t-1}$ & & $\begin{array}{l}-61.29^{* * *} \\
(-32.11)\end{array}$ & $\begin{array}{l}-116.90^{* * *} \\
(-39.53)\end{array}$ & $\begin{array}{l}-60.69^{* * *} \\
(-36.27)\end{array}$ & $\begin{array}{l}-63.09 * * * \\
(-31.15)\end{array}$ & $\begin{array}{l}-60.26^{* * *} \\
(-33.34)\end{array}$ \\
\hline$N e t U p g r_{i, t-1}$ & & $\begin{array}{l}-0.01 * * \\
(-2.07)\end{array}$ & $\begin{array}{l}0.01 \\
(1.44)\end{array}$ & $\begin{array}{l}-0.01^{* *} \\
(-2.13)\end{array}$ & $\begin{array}{l}-0.01^{*} \\
(-1.72)\end{array}$ & $\begin{array}{l}-067 \\
(-0.67)\end{array}$ \\
\hline $1 Q t r \operatorname{Ret}_{i, t-1}$ & & $\begin{array}{l}1.19 \\
(0.33)\end{array}$ & $\begin{array}{l}-1.31 \\
(-0.39)\end{array}$ & $\begin{array}{l}-6.45 \\
(-1.62)\end{array}$ & $\begin{array}{l}-14.46^{* * *} \\
(-3.24)\end{array}$ & $\begin{array}{l}-10.71^{* * *} \\
(-2.67)\end{array}$ \\
\hline $4 Q \operatorname{tr} \operatorname{Ret}_{i, t-1}$ & & $\begin{array}{l}14.68^{* * *} \\
(10.64)\end{array}$ & $\begin{array}{l}16.43^{* * *} \\
(12.52)\end{array}$ & $\begin{array}{l}13.94^{\text {*** }} \\
(8.49)\end{array}$ & $\begin{array}{l}12.83^{\text {*** }} \\
(7.26)\end{array}$ & $\begin{array}{l}13.08^{* * *} \\
(7.47)\end{array}$ \\
\hline Intercept & $\begin{array}{c}-5.44^{* * *} \\
(-13.31)\end{array}$ & $\begin{array}{l}16.13^{* * *} \\
(15.10)\end{array}$ & $\begin{array}{l}37.66^{* * *} \\
(35.19)\end{array}$ & $\begin{array}{l}16.23^{* * *} \\
(15.53)\end{array}$ & $\begin{array}{l}17.58^{* * *} \\
(22.90)\end{array}$ & $\begin{array}{l}16.47^{* * *} \\
(6.73)\end{array}$ \\
\hline Model & OLS & OLS & OLS & OLS & OLS & Fama-MB \\
\hline Fixed Effects & None & None & Permno & Date & Date*SIC-4 & None \\
\hline Cluster SE & SIC-2 & SIC-2 & SIC-2 & SIC-2 & SIC-2 & SIC-2 \\
\hline Observations & 101,272 & 101,272 & 101,272 & 101,272 & 101,272 & 44 \\
\hline F-Statistic & 44.97 & 355.8 & 403.9 & 400.4 & 183.2 & \\
\hline $\mathrm{R}^{2}$ & 0.003 & 0.041 & 0.093 & 0.056 & 0.283 & \\
\hline
\end{tabular}




\section{Table 4: Hedge Fund And Analysts - Count Regressions}

This table presents LPM, Poisson, and negative binomial regressions relating hedge fund buying and selling to analyst upgrade and downgrade reports in the next quarter. The dependent variables are: $U p g r_{i, t}$ and $D n g r_{i, t}$, which are the number of upgrade and downgrade reports published for stock $i$ during quarter $t$. The independent variables of interest are: $H F b u y s_{i, t-1}$ and $H F$ sells $_{i, t-1}$. The variable HFbuys ${ }_{i, t-1}$ is the number of hedge funds buying, and $H F$ sell $_{i, t-1}$ is the number selling stock $i$ during quarter $t-1$. $M$ Fbuys $_{i, t-1}$ and MFbuys $_{i, t-1}$ are similar for mutual funds. Independent variables are de-meaned and divided by standard deviation. The Poisson and negative binomial regressions include an exposure variable $A n_{i, t-1}$ which is the $\log$ of the number of analysts covering. Observations are stock-quarter from 2004-2014. T-statistics are presented in parentheses: $* * *$ indicates significance at $1 \%$ level, ${ }^{* *}$ indicates $5 \%$, and $*$ indicates $10 \%$.

\begin{tabular}{|c|c|c|c|c|c|c|}
\hline & $\begin{array}{c}(1) \\
\operatorname{Upgr}_{i, t} \\
\end{array}$ & $\begin{array}{c}(2) \\
U p g r_{i, t} \\
\end{array}$ & $\begin{array}{c}(3) \\
\text { Upgr }_{i, t} \\
\end{array}$ & $\begin{array}{c}(4) \\
D n g r_{i, t}\end{array}$ & $\begin{array}{c}(5) \\
D n g r_{i, t}\end{array}$ & $\begin{array}{c}(6) \\
D n g r_{i, t}\end{array}$ \\
\hline HFbuys $_{i, t-1}$ & $\begin{array}{l}2.71^{* * *} \\
(5.46)\end{array}$ & $\begin{array}{l}1.06^{* * *} \\
(7.58)\end{array}$ & $\begin{array}{l}1.07^{* * *} \\
(9.62)\end{array}$ & $\begin{array}{l}-1.25^{* * *} \\
(-4.10)\end{array}$ & $\begin{array}{l}0.99^{*} \\
(-2.07)\end{array}$ & $\begin{array}{l}0.99^{*} \\
(-1.63)\end{array}$ \\
\hline$H F$ sell $_{i, t-1}$ & $\begin{array}{l}-1.19^{* * *} \\
(-3.04)\end{array}$ & $\begin{array}{l}0.99^{*} \\
(-1.73)\end{array}$ & $\begin{array}{l}0.99 \\
(-0.52)\end{array}$ & $\begin{array}{l}2.19^{* * *} \\
(5.70)\end{array}$ & $\begin{array}{l}1.05^{* * *} \\
(7.19)\end{array}$ & $\begin{array}{l}1.05^{* * *} \\
(7.96)\end{array}$ \\
\hline$M F b u y s_{i, t-1}$ & $\begin{array}{l}0.72^{* *} \\
(2.20)\end{array}$ & $\begin{array}{l}1.00 \\
(-0.12)\end{array}$ & $\begin{array}{l}1.00 \\
(-0.12)\end{array}$ & $\begin{array}{l}1.08^{* *} \\
(2.13)\end{array}$ & $\begin{array}{l}1.00 \\
(0.25)\end{array}$ & $\begin{array}{l}1.00 \\
(0.12)\end{array}$ \\
\hline$M_{F}$ sells $_{i, t-1}$ & $\begin{array}{l}0.61 \\
(1.59)\end{array}$ & $\begin{array}{l}1.01^{*} \\
(1.77)\end{array}$ & $\begin{array}{l}1.02^{*} \\
(2.90)\end{array}$ & $\begin{array}{l}0.74^{*} \\
(1.81)\end{array}$ & $\begin{array}{l}1.01 \\
(1.37)\end{array}$ & $\begin{array}{l}1.01 \\
(1.32)\end{array}$ \\
\hline Model & OLS & Poisson & NegBin & OLS & Poisson & NegBin \\
\hline Controls & Yes & Yes & Yes & Yes & Yes & Yes \\
\hline Fixed Effects & Date & Date & Date & Date & Date & Date \\
\hline Cluster SE & SIC-2 & SIC-2 & SIC-2 & SIC-2 & SIC-2 & SIC-2 \\
\hline Observations & 101,195 & 101,195 & 101,195 & 101,195 & 101,195 & 101,195 \\
\hline F-Statistic & 125.5 & & & 201.7 & & \\
\hline $\mathrm{R}^{2}$ & 0.171 & & & 0.136 & & \\
\hline Exposure Var & & $A n_{i, t-1}$ & $A n_{i, t-1}$ & & $A n_{i, t-1}$ & $A n_{i, t-1}$ \\
\hline AIC & & 119.5 & 119.0 & & 119.6 & 119.0 \\
\hline $\mathrm{BIC}$ & & 622.3 & 634.0 & & 625.1 & 634.1 \\
\hline
\end{tabular}




\section{Table 5: Hedge Fund and Mutual Fund Trades After Analyst Re- ports}

This table presents OLS regressions relating quarterly analyst upgrades and downgrades to hedge fund trades in the following quarter. The dependent variables are HFnet $_{i, t}$ and MFnet $_{i, t}$ which represent the net direction of the quarterly buying and selling of hedge funds and mutual funds. The independent variables of interest are NetUpgri,t-1, Upgrades $_{i, t-1}$, and Downgrades Det $_{i, 1}$ which indicate the number of analyst upgrade and downgrade reports published by analysts covering stock $i$ during quarter $t$. I de-mean and then divide by the standard deviation for each variable as described in the Data section. Observations are stock-quarter from 2004-2014. T-statistics are presented in parentheses: $* * *$ indicates significance at $1 \%$ level, $* *$ indicates $5 \%$, and $*$ indicates $10 \%$.

\begin{tabular}{|c|c|c|c|c|}
\hline & $\begin{array}{c}(1) \\
\text { HFnet }_{i, t}\end{array}$ & $\begin{array}{c}(2) \\
\text { HFnet }_{i, t}\end{array}$ & $\begin{array}{c}(3) \\
\text { MFnet }_{i, t}\end{array}$ & $\begin{array}{c}(4) \\
M F \text { net }_{i, t}\end{array}$ \\
\hline$N e t U p g r_{i, t-1}$ & $\begin{array}{l}-4.67 * * * \\
(-7.15)\end{array}$ & & $\begin{array}{l}5.48^{* * *} \\
(12.91)\end{array}$ & \\
\hline Upgrades $_{i, t-1}$ & & $\begin{array}{l}-4.49^{* * *} \\
(-8.18)\end{array}$ & & $\begin{array}{l}2.17^{* * *} \\
(4.41)\end{array}$ \\
\hline Downgrades $_{i, t-1}$ & & $\begin{array}{l}0.36 \\
(0.74)\end{array}$ & & $\begin{array}{l}-5.24^{* * *} \\
(-12.27)\end{array}$ \\
\hline Fixed Effects & Date*SIC-4 & Date*SIC-4 & Date*SIC-4 & Date*SIC-4 \\
\hline Cluster SE & SIC-2 & SIC-2 & SIC-2 & SIC-2 \\
\hline Observations & 99,154 & 99,154 & 99,154 & 99,156 \\
\hline F-Statistic & 165.4 & 147.6 & 256.7 & 230.6 \\
\hline $\mathrm{R}^{2}$ & 0.283 & 0.284 & 0.283 & 0.283 \\
\hline
\end{tabular}




\section{Table 6: Hedge Fund and Mutual Fund Performance by Size}

This table presents OLS regressions relating quarterly performance of hedge funds and mutual funds over the 44-quarter time series of my sample. The dependent variable for each regression is $\operatorname{Perf} f_{f, t}$, which is the quarterly marketcap weighted performance of my samples of hedge funds and mutual funds. The independent variable for each regression is $H F_{f}$, which is a dummy variable indicating the hedge fund sample. The columns represent hedge fund and mutual fund performance among stocks sorted into terciles by size. I describe the hedge fund and mutual fund samples in detail in Sections 2.2.1 and 2.2.2. The data are quarterly from 2004-2014. T-statistics (for coefficients) and F-statistics (for differences) are presented in parentheses: *** indicates significance at $1 \%$ level, $* *$ indicates $5 \%$, and $*$ indicates $10 \%$.

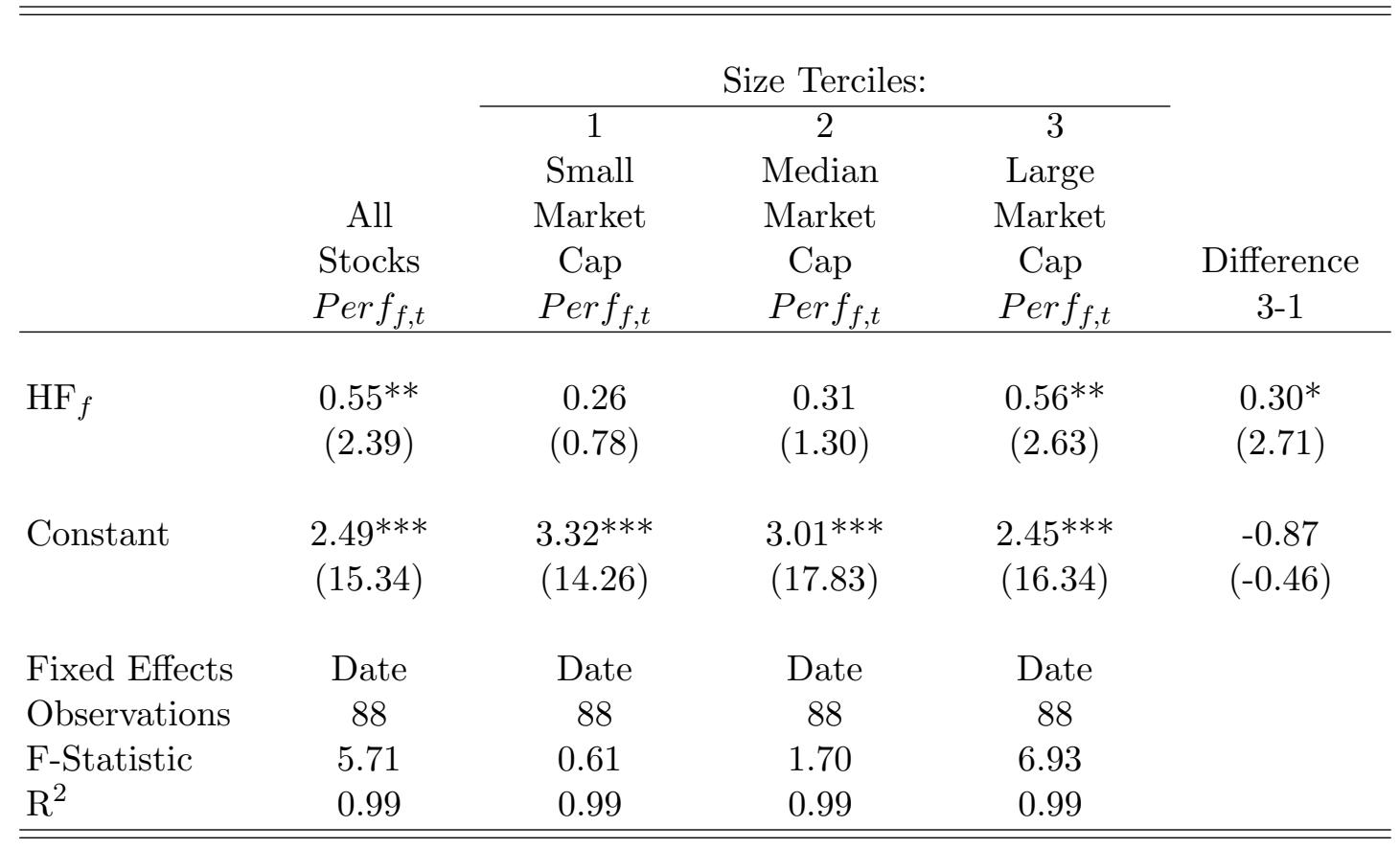




\section{Table 7: Hedge Fund and Mutual Fund Performance by Analyst Coverage}

This table presents OLS regressions relating quarterly performance of hedge funds and mutual funds over the 44-quarter time series of my sample. The dependent variable for each regression is $\operatorname{Per} f_{f, t}$, which is the quarterly marketcap weighted performance of my samples of hedge funds and mutual funds. The independent variable for each regression is $H F_{f}$, which is a dummy variable indicating the hedge fund sample. The columns represent hedge fund and mutual fund performance among stocks double-sorted into terciles by size, and then within each size tercile by the number of analysts covering. I describe the hedge fund and mutual fund samples in detail in Sections 2.2.1 and 2.2.2. The data are quarterly from 2004-2014. T-statistics (for coefficients) and $\mathrm{F}$-statistics (for differences) are presented in parentheses: *** indicates significance at $1 \%$ level, ${ }^{* *}$ indicates $5 \%$, and ${ }^{*}$ indicates $10 \%$.

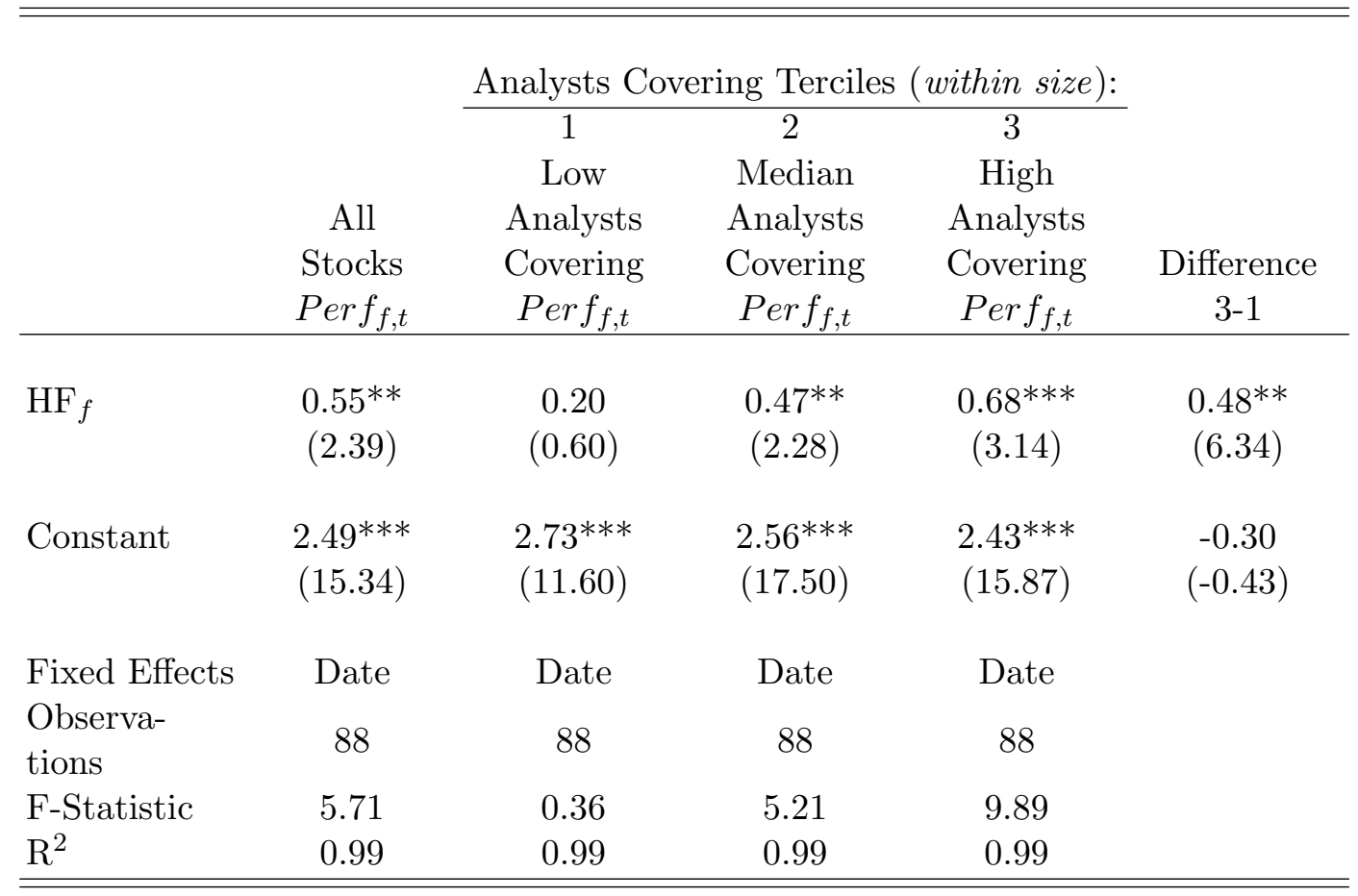




\section{Table 8: Hedge Fund Trades Before Analyst Reports - Coverage Terciles}

This table presents OLS regressions relating quarterly hedge fund net buying in one quarter to analyst net upgrade reports in the next quarter. The dependent variables are: NetUpgr ${ }_{i, t}$ which is the number of upgrade reports minus the number of downgrade report published for stock $i$ during quarter $t$. The independent variable of interest is FFnet $_{i, t-1}$ which is the number of hedge funds buying minus the number of hedge funds selling stock $i$ during quarter $t-1$. These variables are de-meaned and scaled by rolling standard deviation, as described in the Data section. The columns represent the subsamples according to grouping stocks into terciles every quarter according to the number of analysts covering. Observations are stock-quarter from 20042014. T-statistics are presented in parentheses: $* * *$ indicates significance at $1 \%$ level, ${ }^{* *}$ indicates $5 \%$, and $*$ indicates $10 \%$.

\begin{tabular}{|c|c|c|c|c|}
\hline & $\begin{array}{c}(1) \\
\text { All } \\
\text { Analyst } \\
\text { Coverage } \\
\text { NetUpgr }_{i, t}\end{array}$ & $\begin{array}{c}(2) \\
\text { Lowest } \\
\text { Tercile } \\
\text { Analyst } \\
\text { Coverage } \\
\text { NetUpgr }_{i, t}\end{array}$ & $\begin{array}{c}(3) \\
\text { Middle } \\
\text { Tercile } \\
\text { Analyst } \\
\text { Coverage } \\
\text { NetUpgr }_{i, t}\end{array}$ & $\begin{array}{c}(4) \\
\text { Highest } \\
\text { Tercile } \\
\text { Analyst } \\
\text { Coverage } \\
\text { NetUpgr }_{i, t}\end{array}$ \\
\hline HFnet $_{i, t-1}$ & $\begin{array}{l}3.56^{* * *} \\
(7.44)\end{array}$ & $\begin{array}{l}1.64^{*} \\
(1.92)\end{array}$ & $\begin{array}{l}3.41^{* * *} \\
(4.47)\end{array}$ & $\begin{array}{l}5.58^{* * *} \\
(9.23)\end{array}$ \\
\hline Controls & Yes & Yes & Yes & Yes \\
\hline Fixed Effects & Date*SIC4 & Date*SIC4 & Date*SIC4 & Date*SIC4 \\
\hline Cluster SE & SIC-2 & SIC-2 & SIC-2 & SIC-2 \\
\hline Observations & 101,272 & 33,728 & 33,756 & 33,788 \\
\hline F-Statistic & 203.1 & 156.6 & 122.2 & 142.2 \\
\hline $\mathrm{R}^{2}$ & 0.283 & 0.444 & 0.450 & 0.385 \\
\hline
\end{tabular}




\section{Table 9: Hedge Fund Trades Before Analyst Reports - Months}

This table presents OLS regressions relating quarterly hedge fund net buying in one quarter to analyst net upgrade reports in the next quarter. The dependent variable is: $N e t U p g r_{i, t}$ which is the number of upgrade reports minus the number of downgrade reports published for stock $i$ during quarter $t$. The columns represent the intra-quarter month in which the first ratings change reports is published for each quarter $t$, as illustrated in Figure 2.1. The independent variable of interest is $H F$ net $_{i, t-1}$ which is the number of hedge funds buying minus the number of hedge funds selling stock $i$ during quarter $t-1$. These variables are de-meaned and scaled by rolling standard deviation, as described in the Data section. Observations are stock-quarter from 2004-2014. T-statistics are presented in parentheses: *** indicates significance at $1 \%$ level, ** indicates $5 \%$, and * indicates $10 \%$.

\begin{tabular}{|c|c|c|c|c|}
\hline & $\begin{array}{c}(1) \\
\text { All } \\
\text { Reports } \\
\text { NetUpgr } r_{i, t}\end{array}$ & $\begin{array}{c}(2) \\
\text { First } \\
\text { Month } \\
\text { NetUpgr }_{i, t}\end{array}$ & $\begin{array}{c}(3) \\
\text { Second } \\
\text { Month } \\
\text { NetUpgr } r_{i, t}\end{array}$ & $\begin{array}{c}(4) \\
\text { Third } \\
\text { Month } \\
\text { NetUpgr }_{i, t}\end{array}$ \\
\hline$H_{F}$ net $_{i, t-1}$ & $\begin{array}{c}3.56^{* * *} \\
(7.4)\end{array}$ & $\begin{array}{c}1.70^{* * *} \\
(7.4)\end{array}$ & $\begin{array}{c}0.81^{* * *} \\
(4.5)\end{array}$ & $\begin{array}{c}0.28^{*} \\
(1.7)\end{array}$ \\
\hline NetUpgr $r_{i, t}$ 1st Month & & & $\begin{array}{c}-0.01^{* *} \\
(-2.3)\end{array}$ & $\begin{array}{c}-0.02^{* * *} \\
(-8.8)\end{array}$ \\
\hline NetUpgr $r_{i, t}$ 2nd Month & & & & $\begin{array}{c}0.01^{* *} \\
(2.4)\end{array}$ \\
\hline Controls & Yes & Yes & Yes & Yes \\
\hline Fixed Effects & Date*SIC-4 & Date*SIC-4 & Date*SIC-4 $^{*}$ & Date*SIC-4 \\
\hline Cluster SE & SIC-2 & SIC-2 & SIC-2 & SIC-2 \\
\hline Observations & 101,272 & 101,272 & 101,272 & 101,272 \\
\hline F-Statistic & 205.0 & 315.1 & 116.1 & 159.6 \\
\hline $\mathrm{R}^{2}$ & 0.283 & 0.254 & 0.244 & 0.249 \\
\hline
\end{tabular}




\section{Table 10: Hedge Fund Trades Before Analyst Reports - Earnings}

Seasons

This table presents OLS regressions relating quarterly hedge fund net buying in one quarter to analyst net upgrade reports in the next quarter. The dependent variable is: $N e t U p g r_{i, t}$ which is the number of upgrade reports minus the number of downgrade reports published for stock $i$ during quarter $t$. The independent variable of interest is: HFnet $_{i, t-1}$ which is the number of hedge funds buying minus the number selling during quarter $t-1$. These variables are de-meaned and divided by standard deviation, as described in the Data section. The columns correspond to analyst reports made before, during, and after quarterly earnings reports for company $i$ during quarter $t$, as illustrated in Figure 2.1. Observations are stock-quarter from 2004-2014. T-statistics are presented in parentheses: $* * *$ indicates significance at $1 \%$ level, $* *$ indicates $5 \%$, and $*$ indicates $10 \%$.

\begin{tabular}{|c|c|c|c|c|}
\hline & $\begin{array}{c}(1) \\
\text { All } \\
\text { Reports } \\
\text { NetUpgr }{ }_{i, t}\end{array}$ & $\begin{array}{c}(2) \\
\text { Before } \\
\text { Earnings } \\
\text { Season } \\
\text { NetUpgr }{ }_{i, t}\end{array}$ & $\begin{array}{c}(3) \\
\\
\text { Earnings } \\
\text { Season } \\
\text { NetUpgr } r_{i, t}\end{array}$ & $\begin{array}{c}(4) \\
\text { After } \\
\text { Earnings } \\
\text { Season } \\
\text { NetUpgr } \\
i, t\end{array}$ \\
\hline HFnet $_{i, t-1}$ & $\begin{array}{c}3.56^{* * *} \\
(7.4)\end{array}$ & $\begin{array}{c}1.51^{* * *} \\
(6.4)\end{array}$ & $\begin{array}{c}0.29^{* * *} \\
(3.4)\end{array}$ & $\begin{array}{c}1.32^{* * *} \\
(5.3)\end{array}$ \\
\hline NetUpgr ${ }_{i, t}$ Pre-Earn Sn & & & $\begin{array}{l}-0.00 \\
(-0.1)\end{array}$ & $\begin{array}{c}-0.05^{* * *} \\
(-4.1)\end{array}$ \\
\hline NetUpgr $r_{i, t}$ Earn Sn & & & & $\begin{array}{c}-0.05^{* * *} \\
(-3.9)\end{array}$ \\
\hline Controls & Yes & Yes & Yes & Yes \\
\hline Fixed Effects & Date*SIC-4 & Date*SIC-4 & Date*SIC-4 & Date*SIC-4 \\
\hline Cluster SE & SIC-2 & SIC-2 & SIC-2 & SIC-2 \\
\hline Observations & 101,272 & 101,272 & 101,272 & 101,272 \\
\hline F-Statistic & 205.0 & 67.39 & 12.52 & 25.90 \\
\hline $\mathrm{R}^{2}$ & 0.283 & 0.265 & 0.223 & 0.269 \\
\hline
\end{tabular}




\section{Table 11: Different Hedge Funds and Analyst Reports}

This table presents OLS regressions relating hedge fund net buying to the direction of subsequent analyst ratings change reports. The dependent variables are $N e t U p g r_{i, t}$, which is the number of analyst upgrade reports minus the number of analyst downgrade reports. The independent variables of interest are $H_{F n e t} t_{i, t-1}$, which is the number of hedge funds buying minus the number of hedge funds selling stock $i$ during quarter $t-1$. These variables are demeaned and scaled by rolling standard deviation, and hedge funds are grouped into terciles. Observations are stock-quarter from 2004-2014. T-statistics (coefficients) and F-statistics (coefficients tests) are presented in parenthesis: *** indicates significance at $1 \%$ level, ${ }^{* *}$ indicates $5 \%$, and $*$ indicates $10 \%$.

\begin{tabular}{|c|c|c|c|c|}
\hline & $\overline{\text { NetUpgr }}{ }_{i, t}$ & $\overline{N \text { NetUpgr }}{ }_{i, t}$ & NetUpgr $r_{i, t}$ & NetUpgr $_{i, t}$ \\
\hline \multicolumn{5}{|l|}{ Portfolio Size: } \\
\hline HFnet $_{i, t-1}: \mathrm{T} 1$ (small) & $\begin{array}{l}1.11^{* * *} \\
(3.03)\end{array}$ & & & \\
\hline HFnet $_{i, t-1}:$ T2 (med) & $\begin{array}{l}2.24^{* * *} \\
(5.01)\end{array}$ & & & \\
\hline HFnet $_{i, t-1}$ : T3 (large) & $\begin{array}{l}2.49^{* * *} \\
(6.25)\end{array}$ & & & \\
\hline \multicolumn{5}{|l|}{ \# Turnover: } \\
\hline HFnet $_{i, t-1}$ : T1 (low) & & $\begin{array}{l}1.09^{* * *} \\
(3.47)\end{array}$ & & \\
\hline HFnet $_{i, t-1}: \mathrm{T} 2$ (med) & & $\begin{array}{l}0.92^{* *} \\
(2.52)\end{array}$ & & \\
\hline HFnet $_{i, t-1}$ : T3 (high) & & $\begin{array}{l}3.68^{* * *} \\
(7.52)\end{array}$ & & \\
\hline \multicolumn{5}{|l|}{ Ind Concentration: } \\
\hline HFnet $_{i, t-1}:$ T1 (low) & & & $\begin{array}{l}0.93^{* *} \\
(2.36)\end{array}$ & \\
\hline HFnet $_{i, t-1}$ : T2 (med) & & & $\begin{array}{l}1.87^{* * *} \\
(5.67)\end{array}$ & \\
\hline HFnet $_{i, t-1}$ : T3 (high) & & & $\begin{array}{l}2.98^{* * *} \\
(5.95)\end{array}$ & \\
\hline \multicolumn{5}{|l|}{ Coverage Overlap: } \\
\hline HFnet $_{i, t-1}$ : T1 (low) & & & & $\begin{array}{l}-2.30 \\
(-1.20)\end{array}$ \\
\hline HFnet $_{i, t-1}:$ T2 (med) & & & & $\begin{array}{l}2.91^{*} \\
(1.70)\end{array}$ \\
\hline HFnet $_{i, t-1}$ : T3 (high) & & & & $\begin{array}{l}7.71^{* * *} \\
(4.23)\end{array}$ \\
\hline $\begin{array}{l}\text { Coefficient Tests: } \\
\beta_{T 3}-\beta_{T 1}=0\end{array}$ & $1.38^{* *}$ & $2.59^{* * *}$ & $2.05^{* * *}$ & $10.01^{* * *}$ \\
\hline
\end{tabular}




\section{Table 12: Individual Hedge Funds and Individual Analysts}

This table presents OLS regressions relating the trades of individual hedge funds to the subsequent ratings change reports of individual analysts. I divide the sample into two equal periods for each hedge fund: $t-1$ for the first half, and $t+1$ for the second half ( $t=0$ is the mid-point). The dependent variables are Predict ${ }_{j, k, t+1}$, which indicates that the trades of hedge fund $j$ predict the ratings change reports of the analysts at brokerage firm $k$ during the second period. The independent variable of interest is $\beta_{j, k, t-1}$, which indicates that the trades of hedge fund $j$ predict the ratings change reports of brokerage firm $k$ during the first period. Continuous variables are de-meaned and scaled by rolling standard deviation. Observations are individual $j \times k$ (hedge fund $\times$ brokerage firm) pairs. T-statistics are presented in parenthesis: $* * *$ indicates significance at $1 \%$ level, ${ }^{* *}$ indicates $5 \%$, and $*$ indicates $10 \%$.

\begin{tabular}{|c|c|c|c|c|c|}
\hline & $\begin{array}{c}(1) \\
\text { Predict }_{j, k, t+1}\end{array}$ & $\begin{array}{c}(2) \\
\text { Predict }_{j, k, t+1} \\
\end{array}$ & $\begin{array}{c}(3) \\
\text { Predict }_{j, k, t+1}\end{array}$ & $\begin{array}{c}(4) \\
\text { Predict }_{j, k, t+1}\end{array}$ & $\begin{array}{c}(5) \\
\text { Predict }_{j, k, t+1} \\
\end{array}$ \\
\hline Predict $_{j, k, t-1}$ & $\begin{array}{l}1.52^{* * *} \\
(2.60)\end{array}$ & $\begin{array}{l}1.39^{* *} \\
(2.36)\end{array}$ & $\begin{array}{l}1.06^{*} \\
(1.87)\end{array}$ & $\begin{array}{l}1.20^{*} \\
(1.96)\end{array}$ & $\begin{array}{l}1.18^{*} \\
(1.93)\end{array}$ \\
\hline Overlap $_{j, k, t-1}$ & & & $\begin{array}{l}0.25^{*} \\
(1.84)\end{array}$ & & $\begin{array}{l}0.32^{* *} \\
(2.35)\end{array}$ \\
\hline$\#$ Positions $_{j, t=0}$ & & & $\begin{array}{l}0.67^{* * *} \\
(3.71)\end{array}$ & & \\
\hline PortSize $_{j, t=0}$ & & & $\begin{array}{l}-0.10 \\
(-0.76)\end{array}$ & & \\
\hline Turnover $_{j, t=0}$ & & & $\begin{array}{l}0.12 \\
(0.87)\end{array}$ & & \\
\hline IndConcentr $_{j, t=0}$ & & & $\begin{array}{l}0.43^{* * *} \\
(3.44)\end{array}$ & & \\
\hline AvgPredict $_{j, t-1}$ & & & $\begin{array}{l}0.35^{* *} \\
(2.22)\end{array}$ & & \\
\hline Analyst $_{k, t=0}$ & & & & & $\begin{array}{l}0.17 \\
(1.01)\end{array}$ \\
\hline IndConcentr $_{k, t=0}$ & & & & & $\begin{array}{l}0.28 \\
(1.37)\end{array}$ \\
\hline Intercept & $\begin{array}{l}4.87^{* * *} \\
(38.02)\end{array}$ & $\begin{array}{l}4.87^{* * *} \\
(38.08)\end{array}$ & $\begin{array}{l}4.89^{* * *} \\
(39.13)\end{array}$ & $\begin{array}{l}4.88^{* * *} \\
(37.37)\end{array}$ & $\begin{array}{l}4.88^{* * *} \\
(37.22)\end{array}$ \\
\hline Model & OLS & OLS & OLS & OLS & OLS \\
\hline Fixed Effects & None & Broker $k$ & Broker $k$ & $\mathrm{HF} j$ & $\mathrm{HF} j$ \\
\hline Cluster SE & Broker $k$ & $\mathrm{HF} j$ & $\mathrm{HF} j$ & Broker $k$ & Broker $k$ \\
\hline Observations & 44,850 & 44,850 & 44,850 & 44,850 & 44,850 \\
\hline F-Statistic & 6.765 & 5.577 & 4.113 & 3.822 & 2.440 \\
\hline $\mathrm{R}^{2}$ & 0.000 & 0.004 & 0.006 & 0.021 & 0.021 \\
\hline
\end{tabular}


Appendices 


\section{Appendix A}

\section{Robustness Tests}

In this section I outline the construction of several alternative information proxy variables for hedge funds and mutual funds using data from quarterly holdings disclosures, and I show that my results are robust to the use of each of these alternative variables. I also present additional summary data.

\section{A.0.1 Additional Information Proxy Variables for Hedge Funds and Mutual Funds}

Below I outline the construction of additional variables to proxy for aggregated buying and selling among hedge funds and mutual funds. The first of these, HF net shares $1_{i, t}$, summarizes the change in the total number of shares owned by all hedge funds:

$$
\text { HF net shares } 1_{i, t}=\frac{\sum_{j \in H \text { Fsample }} \text { shares }_{j, i, t}-\text { share }_{j, i, t-1}}{\sum_{j \in H \text { Fsample }} \text { shares }_{j, i, t-1}}
$$

As is the case with each of these variables, I construct a similar variable for

mutual funds. An additional alternative variable, HF net shares $2_{i, t}$, scales the change in shares by the total trading volume for stock $i$ during the contempo- 
raneous quarter $t$ as shown below:

$$
\text { HF net shares } 2_{i, t}=\frac{\sum_{j \in H \text { Fsample }} \text { shares }_{j, i, t}-\text { shares }_{j, i, t-1}}{\text { Volume }_{i, t}}
$$

I construct variables to summarize the change in stock $i$ 's share of the aggregated portfolio of hedge funds and mutual funds, which takes into account the portfolio impact of quarterly stock price performance:

$\mathrm{HF}_{\text {port change }}$ pht $_{i, t}=\frac{\sum_{j \in H F s}\left\{\text { shares }_{j, i, t}\right\} * \text { price }_{i, t}}{\sum_{j \in H F s} \text { Portfolio }_{j, i, t}}-\frac{\sum_{j \in H F s}\left\{\text { shares }_{j, i, t-1}\right\} * \text { price }_{i, t-1}}{\sum_{j \in H F s} \text { Portfolio }_{j, i, t-1}}$

The final alternative variable I present is similar to the variable used in my main tests. However, instead of summing all hedge funds that buy during a quarter and subtracting all hedge funds that sell, I only consider hedge funds that initiate positions and only hedge funds that completely close out positions:

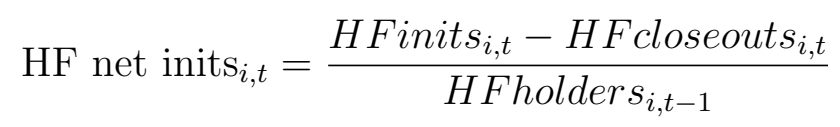

\section{A.0.2 Tests Using Additional Information Proxy Variables}

Appendix Table 1 shows regressions similar to those presented in Column 5 of Table 3, but Appendix Table 1 uses the variables outlined above to proxy for the trading of hedge funds and mutual funds. In addition, each of the independent variables is de-meaned and scaled by standard deviation. 


\section{Table 1: Investor Trades and Analyst Reports - Alternative Mea- sures}

This table presents OLS regressions that relate many proxies for hedge fund trading in one quarter to the direction of analyst ratings change reports in the next quarter. The dependent variable for each regression is $N e t U p g r_{i, t}$, which is the number of analyst upgrade reports minus the number of analyst downgrade reports for stock $i$ during quarter $t$. The independent variables of interest are proxies for aggregated hedge fund and mutual fund buying which are described in the Appendix and the Data section. Each of these variables has been de-meaned and scaled by standard deviation, as described in the Data section. Observations are stock-quarter from 2004-2014. T-statistics are presented in parentheses: ${ }^{* * *}$ indicates significance at $1 \%$ level, ${ }^{* *}$ indicates $5 \%$, and $*$ indicates $10 \%$.

\begin{tabular}{|c|c|c|c|c|c|}
\hline & $\begin{array}{c}(1) \\
N e t U p g r_{i, t} \\
\end{array}$ & $\begin{array}{c}(2) \\
N e t U_{p r} r_{i, t} \\
\end{array}$ & $\begin{array}{c}(3) \\
\text { NetUpgr } \\
\text { i,t }\end{array}$ & $\begin{array}{c}(4) \\
\text { NetUpgr } \\
, t, t\end{array}$ & $\begin{array}{c}(5) \\
N e t U p g r_{i, t} \\
\end{array}$ \\
\hline HFnet $_{i, t-1}$ & $\begin{array}{l}3.63^{* * *} \\
(7.84)\end{array}$ & & & & \\
\hline HF net inits $_{i, t-1}$ & & $\begin{array}{l}3.75 * * * \\
(6.44)\end{array}$ & & & \\
\hline HF net shares $1_{i, t-1}$ & & & $\begin{array}{l}1.18^{* * *} \\
(4.66)\end{array}$ & & \\
\hline HF net shares $2_{i, t-1}$ & & & & $\begin{array}{l}2.31^{* * *} \\
(7.05)\end{array}$ & \\
\hline HF port change $e_{i, t-1}$ & & & & & $\begin{array}{l}1.82^{* * * *} \\
(6.24)\end{array}$ \\
\hline Controls & Yes & Yes & Yes & Yes & Yes \\
\hline Fixed Effects & Date*SIC-4 & Date*SIC-4 & Date*SIC-4 & Date*SIC-4 & Date*SIC-4 \\
\hline Cluster SE & SIC-2 & SIC-2 & SIC-2 & SIC-2 & SIC-2 \\
\hline Observations & 95,756 & 95,755 & 95,013 & 95,755 & 95,530 \\
\hline F-Statistic & 222.7 & 228.4 & 204.8 & 313.1 & 225.6 \\
\hline R-squared & 0.290 & 0.290 & 0.290 & 0.290 & 0.290 \\
\hline
\end{tabular}




\section{Bibliography}

Ackermann, Carl, Richard McEnally, and David Ravenscraft, 1999, The performance of hedge funds: Risk, return, and incentives, The journal of $\mathrm{Fi}$ nance 54, 833-874.

Agarwal, Vikas, Vyacheslav Fos, and Wei Jiang, 2013, Inferring reportingrelated biases in hedge fund databases from hedge fund equity holdings, Management Science 59, 1271-1289.

Agarwal, Vikas, Wei Jiang, Yuehua Tang, and Baozhong Yang, 2013, Uncovering hedge fund skill from the portfolio holdings they hide, The Journal of Finance 68, 739-783.

Almazan, Andres, Keith C Brown, Murray Carlson, and David A Chapman, 2004, Why constrain your mutual fund manager?, Journal of Financial Economics 73, 289-321.

Ben-David, Itzhak, Francesco Franzoni, and Rabih Moussawi, 2012, stock trading in the financial crisis of 2007-2009, Review of Financial Studies $25,1-54$.

Bennett, James A, Richard W Sias, and Laura T Starks, 2003, Greener pastures and the impact of dynamic institutional preferences, Review of Financial Studies 16, 1203-1238.

Blocher, Jesse, 2014, Network externalities in mutual funds, Vanderbilt Owen Graduate School of Management Research Paper .

Brav, Alon, Wei Jiang, and Hyunseob Kim, 2009, Hedge fund activism: A review, Foundations and Trends in Finance 4, 185-246.

Brav, Alon, Wei Jiang, Frank Partnoy, and Randall Thomas, 2008, Hedge fund activism, corporate governance, and firm performance, The Journal of Finance 63, 1729-1775. 
Brown, Nerissa C, Kelsey D Wei, and Russ Wermers, 2013, Analyst recommendations, mutual fund herding, and overreaction in stock prices, Management Science 60, 1-20.

Brown, Stephen J and Christopher Schwarz, 2011, The impact of mandatory hedge fund portfolio disclosure, Available at SSRN 1683628 .

Brunnermeier, Markus K and Stefan Nagel, 2004, Hedge funds and the technology bubble, The Journal of Finance 59, 2013-2040.

Busse, Jeffrey A, T Clifton Green, and Narasimhan Jegadeesh, 2012, Buy-side trades and sell-side recommendations: Interactions and information content, Journal of Financial Markets 15, 207-232.

Cao, H Henry, Joshua D Coval, and David Hirshleifer, 2002, Sidelined investors, trading-generated news, and security returns, Review of Financial Studies 15, 615-648.

Carhart, Mark M, 1997, On persistence in mutual fund performance, The Journal of Finance 52, 57-82.

Chen, Joseph, Harrison Hong, and Jeremy C Stein, 2002, Breadth of ownership and stock returns, Journal of Financial Economics 66, 171-205.

Christophe, Stephen E, Michael G Ferri, and James J Angel, 2004, Shortselling prior to earnings announcements, The Journal of Finance 59, 18451876.

Clifford, Christopher P, 2008, Value creation or destruction? hedge funds as shareholder activists, Journal of Corporate Finance 14, 323-336.

Coval, Joshua and Erik Stafford, 2007, Asset fire sales (and purchases) in equity markets, Journal of Financial Economics 86, 479-512.

Cremers, KJ Martijn and Antti Petajisto, 2009, How active is your fund manager? a new measure that predicts performance, Review of Financial Studies 22, 3329-3365. 
Daniel, Kent, Mark Grinblatt, Sheridan Titman, and Russ Wermers, 1997, Measuring mutual fund performance with characteristic-based benchmarks, Journal of Finance 1035-1058.

Fama, Eugene F and Kenneth R French, 2010, Luck versus skill in the crosssection of mutual fund returns, The Journal of Finance 65, 1915-1947.

Fama, Eugene F and James D MacBeth, 1973, Risk, return, and equilibrium: Empirical tests, The Journal of Political Economy 607-636.

French, Kenneth R, 2008, Presidential address: The cost of active investing, The Journal of Finance 63, 1537-1573.

Gargano, Antonio, Alberto G Rossi, and Russ Wermers, 2014, The freedom of information act and the race towards information acquisition, Available at SSRN 2517075 .

Gaspar, José-Miguel, Massimo Massa, and Pedro Matos, 2005, Shareholder investment horizons and the market for corporate control, Journal of Financial Economics 76, 135-165.

Griffin, John M and Jin Xu, 2009, How smart are the smart guys? a unique view from hedge fund stock holdings, Review of Financial Studies 22, 25312570 .

Grinblatt, Mark and Sheridan Titman, 1989, Mutual fund performance: An analysis of quarterly portfolio holdings, Journal of Business 393-416.

Groysberg, Boris, Paul M Healy, and David A Maber, 2011, What drives sell-side analyst compensation at high-status investment banks?, Journal of Accounting Research 49, 969-1000.

Hirshleifer, David, Avanidhar Subrahmanyam, and Sheridan Titman, 1994, Security analysis and trading patterns when some investors receive information before others, Journal of Finance 1665-1698.

Hong, Harrison, Terence Lim, and Jeremy C Stein, 2000, Bad news travels slowly: Size, analyst coverage, and the profitability of momentum strategies, The Journal of Finance 55, 265-295. 
Ibbotson, Roger G and Peng Chen, 2005, Sources of hedge fund returns: Alphas, betas, and costs, Yale ICF Working Paper 5, 17.

Irvine, Paul, Marc Lipson, and Andy Puckett, 2007, Tipping, Review of Financial Studies 20, 741-768.

Irvine, Paul J, 2003, The incremental impact of analyst initiation of coverage, Journal of Corporate Finance 9, 431-451.

Jeng, Daniel H, 2013, Expert networks and insider trading: An introduction and recommendation .

Kacperczyk, Marcin and Amit Seru, 2007, Fund manager use of public information: New evidence on managerial skills, The Journal of Finance 62, $485-528$.

Kacperczyk, Marcin, Clemens Sialm, and Lu Zheng, 2005, On the industry concentration of actively managed equity mutual funds, The Journal of Finance 60, 1983-2011.

Kacperczyk, Marcin, Clemens Sialm, and Lu Zheng, 2008, Unobserved actions of mutual funds, Review of Financial Studies 21, 2379-2416.

Kadan, Ohad, Roni Michaely, and Pamela C Moulton, 2014, Speculating on private information: Buy the rumor, sell the news, Available at SSRN: 2427282.

Klein, April, Anthony Saunders, and Yu Ting Forester Wong, 2014, Do hedge funds trade on private information? evidence from upcoming changes in analysts' stock recommendations, Available at SSRN 2421801 .

Kosowski, Robert, Narayan Y Naik, and Melvyn Teo, 2007, Do hedge funds deliver alpha? a bayesian and bootstrap analysis, Journal of Financial Economics 84, 229-264.

Ljungqvist, Alexander and Wenlan Qian, 2014, How constraining are limits to arbitrage? evidence from a recent financial innovation, Working paper, National Bureau of Economic Research. 
Ramnath, Sundaresh, Steve Rock, and Philip Shane, 2008, The financial analyst forecasting literature: A taxonomy with suggestions for further research, International Journal of Forecasting 24, 34-75.

Senchack, Andrew J and Laura T Starks, 1993, Short-sale restrictions and market reaction to short-interest announcements, Journal of Financial and quantitative analysis 28, 177-194.

Sias, Richard W, Laura T Starks, and Sheridan Titman, 2001, The price impact of institutional trading, Available at SSRN 283779 .

Solomon, David H and Eugene F Soltes, What are we meeting for? the consequences of private meetings with investors, The Consequences of Private Meetings with Investors (January 30, 2013) (2013).

Starks, Laura T, 1987, Performance incentive fees: An agency theoretic approach, Journal of Financial and Quantitative Analysis 22, 17-32.

Stein, Jeremy C, 2009, Presidential address: Sophisticated investors and market efficiency, The Journal of Finance 64, 1517-1548.

Stulz, René M, 2007, Hedge funds: Past, present, and future, The Journal of Economic Perspectives 21, 175-194.

Verbeek, Marno and Yu Wang, 2013, Better than the original? the relative success of copycat funds, Journal of Banking $\mathcal{E}$ Finance 37, 3454-3471.

Wermers, Russ, 2000, Mutual fund performance: An empirical decomposition into stock-picking talent, style, transactions costs, and expenses, The Journal of Finance 55, 1655-1703.

Womack, Kent L, 1996, Do brokerage analysts' recommendations have investment value?, Journal of Finance 137-167. 